\title{
Article \\ CFD Simulation and Experimental Study on Coupled Motion Response of Ship with Tank in Beam Waves
}

\author{
Tao He ${ }^{1}$, Dakui Feng ${ }^{1, *}$, Liwei Liu ${ }^{1}$, Xianzhou Wang ${ }^{1}$ and Hua Jiang ${ }^{2}$ \\ 1 Key Laboratory of Ship and Ocean Hydrodynamics, School of Naval Architecture and Ocean Engineering, \\ Huazhong University of Science and Technology, Wuhan 430074, China; m202071783@hust.edu.cn (T.H.); \\ llw@hust.edu.cn (L.L.); wangxz@hust.edu.cn (X.W.) \\ 2 Guangzhou Marine Engineering Corporation, Guangzhou 510250, China; jiangh@gumeco.com \\ * Correspondence: feng_dk@hust.edu.cn
}

check for updates

Citation: He, T.; Feng, D.; Liu, L.; Wang, X.; Jiang, H. CFD Simulation and Experimental Study on Coupled Motion Response of Ship with Tank in Beam Waves. J. Mar. Sci. Eng. 2022, 10, 113. https://doi.org/10.3390/ jmse10010113

Academic Editors: Tahsin Tezdogan, Md Jahir Rizvi and Jialong Jiao

Received: 25 November 2021

Accepted: 12 January 2022

Published: 14 January 2022

Publisher's Note: MDPI stays neutral with regard to jurisdictional claims in published maps and institutional affiliations.

Copyright: (C) 2022 by the authors. Licensee MDPI, Basel, Switzerland. This article is an open access article distributed under the terms and conditions of the Creative Commons Attribution (CC BY) license (https:// creativecommons.org/licenses/by/ $4.0 /)$.

\begin{abstract}
Tank sloshing is widely present in many engineering fields, especially in the field of marine. Due to the trend of large-scale liquid cargo ships, it is of great significance to study the coupled motion response of ships with tanks in beam waves. In this study, the CFD (Computational Fluid Dynamics) method and experiments are used to study the response of a ship with/without a tank in beam waves. All the computations are performed by an in-house CFD solver, which is used to solve RANS (Reynold Average Navier-Stokes) equations coupled with six degrees-of-freedom solid-body motion equations. The Level Set Method is used to solve the free surface. Verification work on the grid number and time step size has been conducted. The simulation results agree with the experimental results well, which shows that the numerical method is accurate enough. In this paper, several different working conditions are set up, and the effects of the liquid height in the tank, the size of the tank and the wavelength ratio of the incident wave on the ship's motion are studied. The results show the effect of tank sloshing on the ship's motion in different working conditions.
\end{abstract}

Keywords: tank sloshing; CFD; experiment; coupling effects; ship motion

\section{Introduction}

Tank sloshing is possible for ships with tanks under almost all loading conditions (except full load and no-load), and tank sloshing has a great impact on all kinds of ships with large tanks. When the external incentive increases or its frequency is close to the natural frequency of the liquid in the tank, it leads to severe sloshing and a huge local impact load, which may cause damage to the bulkhead. The interaction between tank sloshing and ship motions cannot be analyzed separately, and the coupling effect between the hull and the tank should be considered.

Sloshing is a complex problem, which has been deeply studied, and some important results have been achieved in recent years. Many scholars have fully studied coupled motion response by means of experiments and numerical simulations. The sloshing problem first appeared in aerospace and nuclear industries. In the 1960s, Abramson [1] studied the sloshing problem of cylindrical and spherical tanks based on the classical potential flow hypothesis and analyzed the influence of dynamic pressure produced by sloshing fluid on the tank. In the 1990s, Ikeda et al. [2] carried out theoretical and experimental studies on the nonlinear vibration of a structure coupled with water in a rectangular tank and provided the modal equation of sloshing and the resonance curve of the system. The theoretical results are in good agreement with the experimental results. Faltinsen et al. [3] derived a three-dimensional discrete mode system to describe the nonlinear sloshing of incompressible fluid based on the nonlinear potential flow theory and provided the representative formula of the hydrodynamic load. Based on the previous work, they established an adaptive program for a wide range of excitation cycles in 2001. The steady-state calculation 
results of wave height, horizontal force and pitching moment were verified by experiments, and the new model agreed well with the experiments [4].

The experimental method is a very important method to study ship motions coupled with tank sloshing. The data obtained by the experimental method can be compared with numerical computation solutions and theoretical solutions. In recent years, many scholars have conducted a lot of research on tank sloshing using experiments. Nasar et al. [5] studied the anti-rolling effect of the porous baffle at the position of $\mathrm{L} / 3$ and $2 \mathrm{~L} / 3$ in the flume tank, where $\mathrm{L}$ is the tank length. The results show that it is effective to set the porous baffle at L/3 and 2L/3 in the flume tank. Nasar et al. [6] also studied the interaction between cargo motions and internal liquid sloshing through experiments. The results show that the rolling response decreases obviously when the excitation wave frequency is equal to the first-order natural sloshing frequency of the liquid in the tank. Shuya Wang et al. [7] carried out an experiment on the tank sloshing and its influence on the rolling motion of the FLNG (Floating Liquefied Natural Gas) system. The study shows that the sloshing degree of the tank in the stern is more intense than that of the bow, and the phase of the tank's liquid level changing in the stern is more consistent. When the tank filling is different, the tank sloshing can not only increase but also reduce the rolling motion response of the ship. Lee et al. [8] carried out a model experiment to examine the effect of the difference between density ratio and phase transition on sloshing's impact. The results show that when external pressure is applied under boiling conditions, it is confirmed that liquefaction occurred inside the gas pocket and the compressibility of the gas is reduced so that not only the oscillation of the impact pressure is reduced, but the damping effect and pressure rise time also increased. Gurusamy et al. [9] conducted a series of experiments to investigate nonlinear shallow water sloshing in detail. It was found that the resonant frequency is sensitive to the excitation amplitude and dispersion parameter (ratio of water-depth to tank-length). For a tank with a large aspect ratio under a high excitation amplitude, it was also found that the resonance frequency increases by about $45 \%$ in comparison to the linear sloshing frequency.

Compared with the ship model test, CFD is another more economical and effective method for studying the interaction between a ship and a tank. A ship CFD simulation can not only save a lot of time and cost but also provide detailed information, such as the force between the hull and tank and external flow field. Bulian et al. [10] studied the dynamics of ship sloshing in the time domain by means of a joint simulation. The simulation results show a nonlinear phenomenon and show that the proposed method can identify the decrease in flume tank efficiency when the length of the tank is too small and the steepness of the wave is too large. Green et al. [11] proposed a smooth particle hydrodynamics formulation to simulate long-duration violent sloshing in partially filled tanks of arbitrary shapes. The simulation results show that the method can reproduce the sloshing force quite accurately and predict the transition to rotating wave motion. Li et al. [12] simulated the time-domain coupling response of tank sloshing and ship motion based on OpenFOAM (Open Field Operation and Manipulation) in Shanghai, China, fully considering the interaction of wave, hull and tank sloshing. The numerical results are in good agreement with the experimental results. Based on OpenFOAM, Jiang et al. [13] carried out a numerical simulation of the coupling effect between ship motion and tank sloshing of a simplified LNG-FPSO (Liquefied Natural Gas-Floating Production Storage and Offloading, the equipment is from Korea) ship with a prismatic tank filled with two parts of waves. The numerical simulation results show that the coupling effect is obvious under the action of transverse waves and the tank filling ratio is low, showing typical anti-rolling characteristics. Based on the linear potential flow theory, Seo et al. [14] studied the coupling between tank sloshing and ship motion and the additional force and torque acting on the hull. The results show that the sloshing flow in the tank has a significant influence not only on the motion response but also on the additional resistance. Su et al. [15] studied the coupling effect between barge motion and tank sloshing in the frequency domain and time domain. The numerical results in the frequency domain and time domain were compared 
with the experimental results. The results show that the coupling motion is significant when the natural frequency of rolling is close to the first-order natural frequency of the liquid in the tank. Shah et al. [16] studied the hybrid nanofluid flow with free convection in a permeable media using CVFEM (Control Volume Finite Element Method). A hybrid nanoparticle $\left(\mathrm{Fe}_{3} \mathrm{O}_{4}+\mathrm{MWCNT}\right.$ (Multi-Walled Carbon Nano Tube)) with a base fluid of $\mathrm{H}_{2} \mathrm{O}$ had been assumed in the study. The results show that the transmission mode enhances when Ha is augmented. Moreover, the study proved that augmenting the porousness factor can increase the Nusselt number, but converse performance is conveyed for Lorentz forces.

We studied a ship with/without a tank in regular beam waves through an experiment. Moreover, based on the solution of the structural overset grid and multi-degree-of-freedom motion, the CFD method is used to study the two-way coupling characteristics of tank sloshing and ship motion. All the conditions are simulated by the in-house CFD solver. The RANS equations are discretized by the finite difference method (FDM). Compared with the potential theory, the RANS method takes into account the viscosity of water, which can accurately simulate sloshing. Verification work on the grid number and time step size has been conducted. The CFD results are in good agreement with the EFD (Experimental Fluid Dynamics) results, which also indicates that the result of the tank sloshing simulated by the in-house CFD code is reliable. From the CFD and EFD results, we can obtain the effects of the liquid height in the tank, the size of the tank and the wavelength ratio of the incident wave on the ship motion in several different working conditions. Finally, the shape of the free surface in the tank at different times is monitored in the simulation.

\section{Model Test}

\subsection{Ship Geometry}

The model consists of two parts: one is the external hull, and the other is the internal tank. When the ship is with/without a tank and with different sizes of tanks, the physical properties, such as displacement, height of center of gravity and transverse mass inertia, remain unchanged. Table 1 shows the main parameters of the model (hull and tank). Figure 1 shows the model size parameters, and Figure 2 shows the experimental model and the scene of making waves in the towing tank.

Table 1. The general properties.

\begin{tabular}{|c|c|c|}
\hline \multirow{4}{*}{ Tank } & Length & $0.57 \mathrm{~m} / 1.17 \mathrm{~m}$ \\
\hline & Width & $0.57 \mathrm{~m}$ \\
\hline & Height & $0.5 \mathrm{~m}$ \\
\hline & Liquid level height & $0.1 \mathrm{~m} / 0.2 \mathrm{~m}$ \\
\hline \multirow{6}{*}{ Hull } & Length & $3 \mathrm{~m}$ \\
\hline & Width & $1 \mathrm{~m}$ \\
\hline & Height & $0.6 \mathrm{~m}$ \\
\hline & Draft & $0.1 \mathrm{~m}$ \\
\hline & Displacement & $0.3781 \mathrm{t}$ \\
\hline & Crosswise moment of inertia & $33.53 \mathrm{~kg} . \mathrm{m}^{2}$ \\
\hline
\end{tabular}

In order to monitor the pressure on the bulkhead of the tank, pressure sensors are used to measure the pressure of seven points on the side bulkhead of the tank. The arrangement diagram of these seven points is shown in Figure 3. Later in the study, we mainly focus on the pressure changes of point 5 and point 7 . Table 2 shows the parameters of the measuring instrument. Before the experiment, all the measuring instruments are calibrated to ensure that the measured values are accurate enough.

Some measuring equipment in the experiment is showing in the Figure 4. 


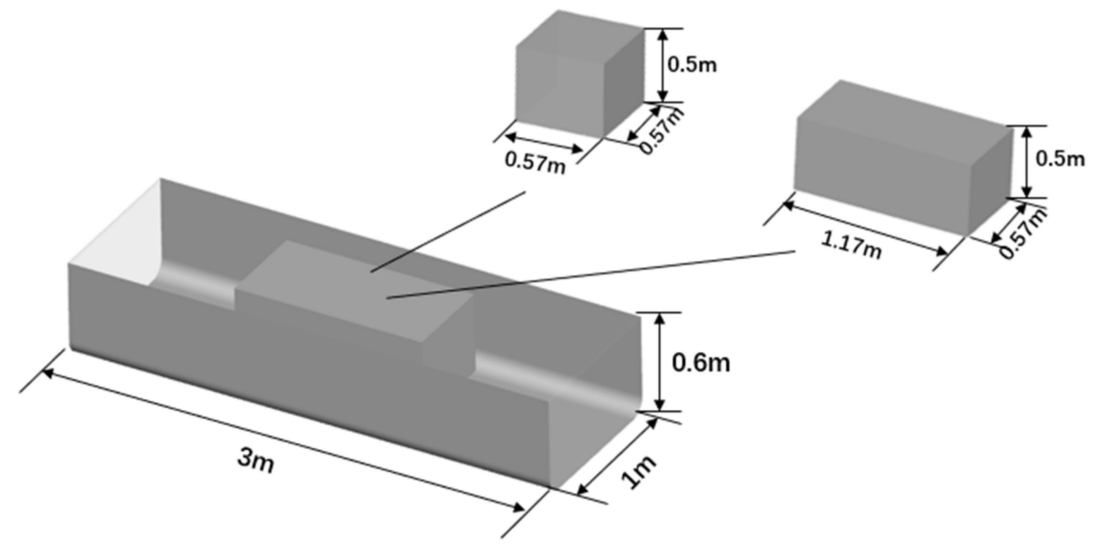

Figure 1. Model size parameters.

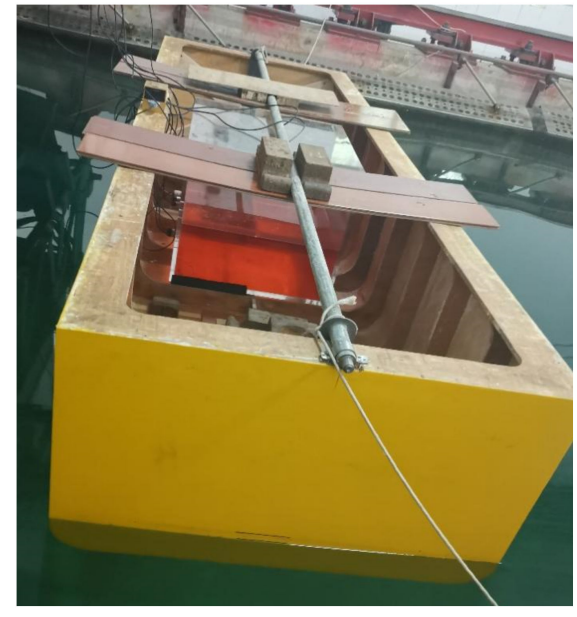

(a)

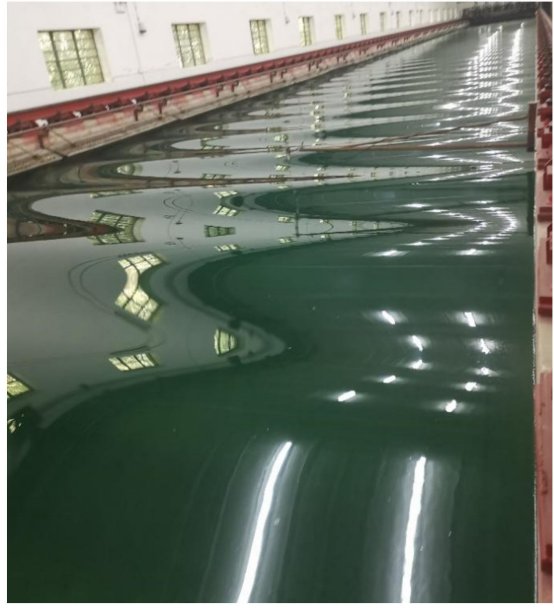

(b)

Figure 2. Experimental model and wave making (a) The experimental model; (b) The scene of making waves.

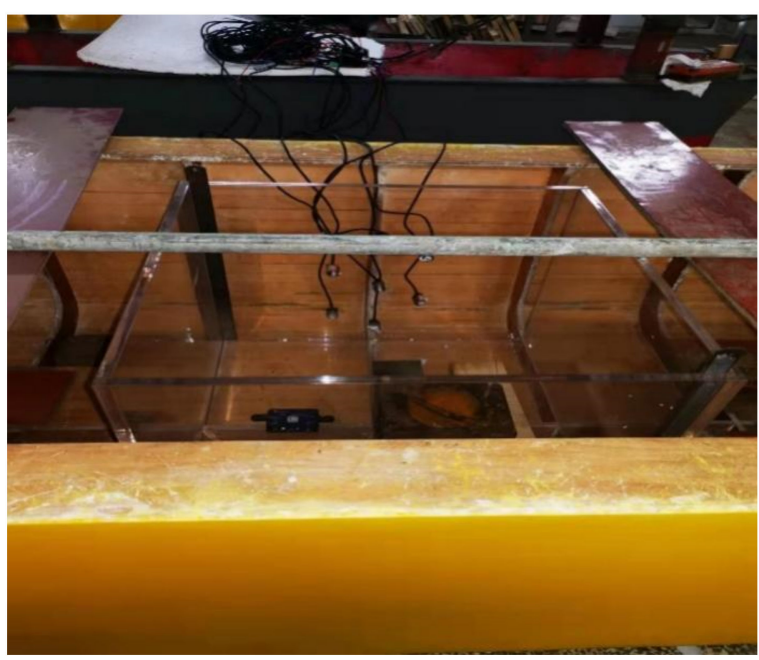

(a)

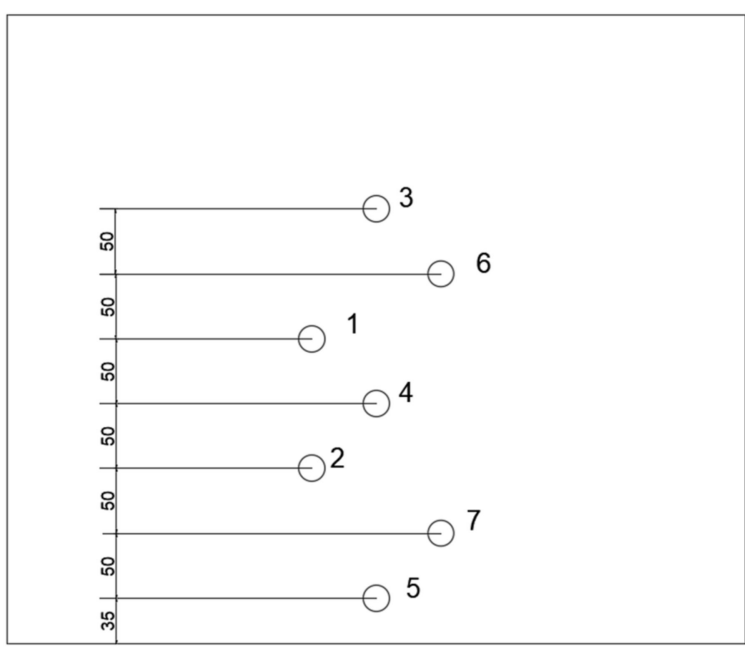

(b)

Figure 3. The layout of the pressure sensor for the side bulkhead of the tank (a) The pressure sensor and the tank; (b) The layout of the pressure sensor. 
Table 2. The properties of the measuring equipment.

\begin{tabular}{ccc}
\hline & \multicolumn{1}{c}{ type number } & VG440 \\
\cline { 2 - 3 } Angle measuring instrument & Measured parameters & Roll \\
\cline { 2 - 3 } & Range of measurement & $\pm 90^{\circ}$ \\
\cline { 2 - 3 } Pressure transducer & Static precision & $0.5 \%$ F.S. \\
\cline { 2 - 3 } & type number & CYY28 \\
\cline { 2 - 3 } & Range of measurement & $0-20 \mathrm{kpa}$ \\
\hline
\end{tabular}

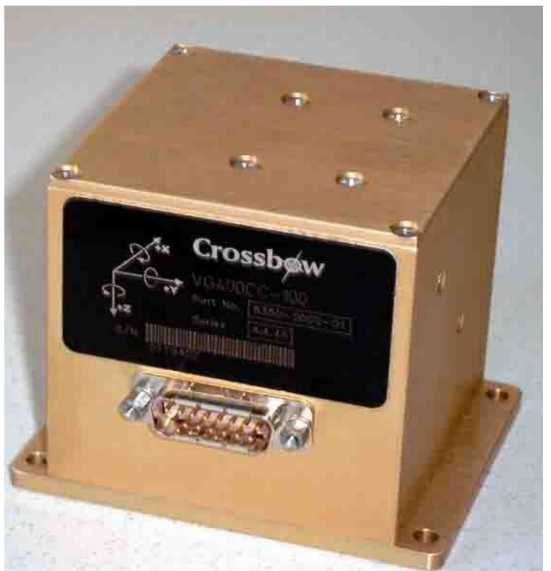

(a)

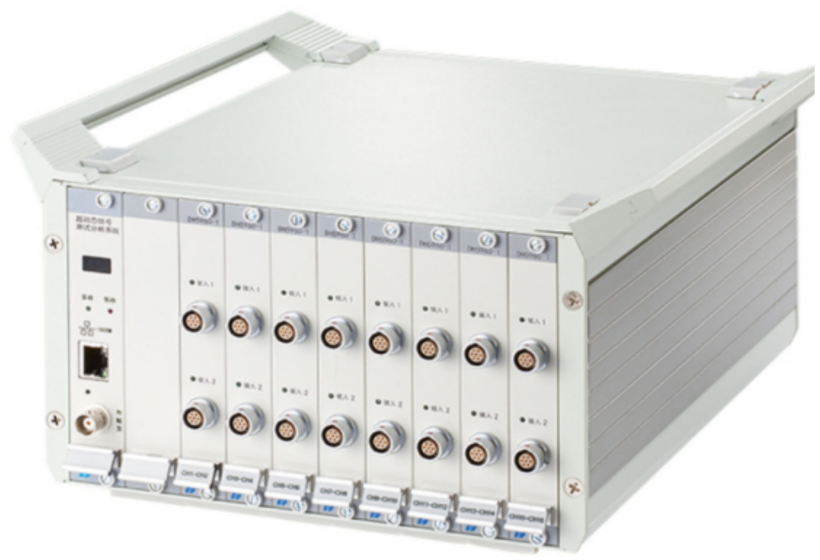

(b)

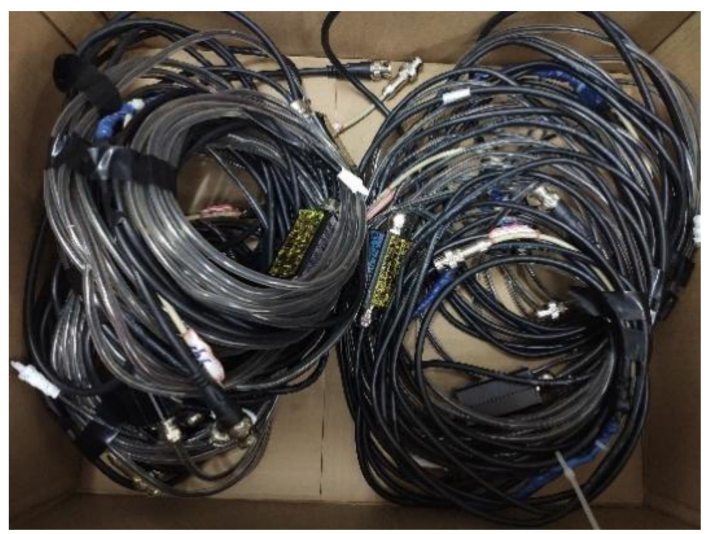

(c)

Figure 4. Measuring equipment in the experiment (a) The Angle measuring instrument; (b) The data acquisition instrument; (c) The pressure sensor.

\subsection{Working Conditions}

The model test was carried out in the towing tank at Huazhong University of Science and Technology, which is a member of the ITTC (International Towing Tank Conference). The towing tank measures $175 \mathrm{~m}$ long, $6 \mathrm{~m}$ wide and $4 \mathrm{~m}$ deep and is equipped with multiple wave makers. When the test model is placed in the towing tank, the wave makers generate beam waves on the hull, and the sloshing force produced by the liquid in the tank also acts on the hull, while the sloshing of the tank is caused by the sloshing of the hull. We measure the roll angle and bulkhead pressure of the tank by experimental equipment, such as angle measuring instruments and pressure sensors. The free rolling attenuation test of the ship model is carried out before the test. The natural rolling period of the ship model is $1.23 \mathrm{~s}$. According to the Faltinsen theory [17], the natural period of the ship model is $1.207 \mathrm{~s}$ 
when the height of the liquid in the tank is $0.1 \mathrm{~m}$. The wavelength selection is shown in Table 3 .

Table 3. Wave parameters in the EFD and CFD.

\begin{tabular}{|c|c|c|c|c|}
\hline & Wavelength/m & Wave Period/s & EFD & CFD \\
\hline \multirow{5}{*}{ Without Tank } & 1.390 & 0.944 & $\sqrt{ }$ & $\sqrt{ }$ \\
\hline & 2.362 & 1.230 & $\sqrt{ }$ & $\sqrt{ }$ \\
\hline & 3.997 & 1.600 & $\sqrt{ }$ & \\
\hline & 6.245 & 2.000 & $\sqrt{ }$ & \\
\hline & 8.000 & 2.264 & $\sqrt{ }$ & $\sqrt{ }$ \\
\hline \multirow{5}{*}{$\begin{array}{l}\text { Tank size: } 0.57 \mathrm{~m} \times 0.57 \mathrm{~m} \times 0.5 \mathrm{~m} \\
\text { The height of water in the tank: } 0.1 \mathrm{~m}\end{array}$} & 1.390 & 0.944 & $\sqrt{ }$ & $\sqrt{ }$ \\
\hline & 2.362 & 1.230 & $\sqrt{ }$ & $\sqrt{ }$ \\
\hline & 3.997 & 1.600 & $\sqrt{ }$ & \\
\hline & 6.245 & 2.000 & $\sqrt{ }$ & \\
\hline & 8.000 & 2.264 & $\sqrt{ }$ & $\sqrt{ }$ \\
\hline \multirow{5}{*}{$\begin{array}{l}\text { Tank size: } 0.57 \mathrm{~m} \times 0.57 \mathrm{~m} \times 0.5 \mathrm{~m} \\
\text { The height of water in the tank: } 0.2 \mathrm{~m}\end{array}$} & 1.390 & 0.944 & $\sqrt{ }$ & $\sqrt{ }$ \\
\hline & 2.362 & 1.230 & $\sqrt{ }$ & $\sqrt{ }$ \\
\hline & 3.997 & 1.600 & $\sqrt{ }$ & \\
\hline & 6.245 & 2.000 & $\sqrt{ }$ & \\
\hline & 8.000 & 2.264 & $\sqrt{ }$ & $\sqrt{ }$ \\
\hline \multirow{5}{*}{$\begin{array}{l}\text { Tank size: } 1.17 \mathrm{~m} \times 0.57 \mathrm{~m} \times 0.5 \mathrm{~m} \\
\text { The height of water in the tank: } 0.1 \mathrm{~m}\end{array}$} & 1.390 & 0.944 & $\sqrt{ }$ & $\sqrt{ }$ \\
\hline & 2.362 & 1.230 & $\sqrt{ }$ & $\sqrt{ }$ \\
\hline & 3.997 & 1.600 & $\sqrt{ }$ & \\
\hline & 6.245 & 2.000 & $\sqrt{ }$ & \\
\hline & 8.000 & 2.264 & $\sqrt{ }$ & $\sqrt{ }$ \\
\hline
\end{tabular}

\section{Numerical Modelling}

In this study, the CFD method based on the structural overset grid and the direct solution of multi-degree of freedom motions are used to study the coupled properties of tank sloshing and ship motion. All the CFD simulations are carried out by the in-house CFD solver. Up to now, there are a few pieces of research on ship motion in waves using the in-house CFD solver $[18,19]$. In these studies, the simulation results by the in-house CFD solver of ship motion in waves are in good agreement with the experimental results. We use the finite difference method to discretize the RANS equation. The viscosity of water cannot be ignored in the sloshing. Compared with the potential theory, the RANS method takes into account the viscosity of water, which can accurately simulate sloshing. The coupling of pressure and velocity is solved by the projection algorithm. A two-equation Shear Stress Transport (SST) $k-\omega$ turbulence model is used.

\subsection{Governing Equations and Turbulent Model}

The turbulence model used in the computation is SST $k-\omega$, which was proposed by Menter [20] in 1994. The N-S (Navier-Stokes) equation of incompressible fluid is dimensionless by relative velocity $\mathrm{U}_{0}$ and characteristic length $\mathrm{L}$. The unsteady incompressible RANS equations are solved by the in-house CFD code:

$$
\frac{\partial U_{i}^{*}}{\partial x_{i}^{*}}=0
$$




$$
\frac{\partial U_{i}^{*}}{\partial t^{*}}+U_{j}^{*} \frac{\partial U_{i}^{*}}{\partial x_{j}^{*}}=-\frac{\partial \bar{p}}{\partial x_{i}^{*}}+\frac{\partial}{\partial x_{j}^{*}}\left(\frac{1}{R e} \frac{\partial U_{i}^{*}}{\partial x_{j}^{*}}-\overline{u_{i}^{*} u_{j}^{*}}\right)
$$

where $U_{i}^{*}$ is the dimensionless average velocity, $\bar{p}$ is the pressure coefficient and $\rho$ means the fluid density. $x_{i}$ means the direction of the coordinates, and $\overline{u_{i}^{*} u_{j}^{*}}$ is the Reynolds stress. The following is about the SST $k-\omega$ turbulence model:

$$
\begin{gathered}
\frac{\partial k}{\partial t}+U_{i} \frac{\partial k}{\partial x_{i}}=P_{k}-\beta^{*} k \omega+\frac{\partial}{\partial x_{i}}\left[\left(v+\sigma_{k} v_{t}\right) \frac{\partial k}{\partial x_{i}}\right] \\
\frac{\partial \omega}{\partial t}+U_{i} \frac{\partial \omega}{\partial x_{i}}=\alpha S^{2}-\beta \omega^{2}+\frac{\partial}{\partial x_{i}}\left[\left(v+\sigma_{\omega} v_{t}\right) \frac{\partial \omega}{\partial x_{i}}\right]+2\left(1-F_{1}\right) \sigma_{\omega 2} \frac{1}{\omega} \frac{\partial k}{\partial x_{i}} \frac{\partial \omega}{\partial x_{i}}
\end{gathered}
$$

where $k$ is the turbulent kinetic energy, $\omega$ is the specific turbulent dissipation rate and $F_{1}$ is the mixing function of the combination of $k-\omega$ and $k-\varepsilon$ models, which is defined as follows:

$$
\begin{gathered}
F_{1}=\tanh \left\{\left\{\min \left[\max \left(\frac{\sqrt{k}}{\beta^{*} \omega y}, \frac{500 v}{y^{2} \omega}\right), \frac{4 \rho \sigma_{\omega 2} k}{C D_{k \omega} y^{2}}\right]\right\}^{4}\right\} \\
C D_{k \omega}=\max \left(2 \rho \sigma_{\omega 2} \frac{1}{\omega} \frac{\partial k}{\partial x_{i}} \frac{\partial \omega}{\partial x_{i}}, 10^{-10}\right)
\end{gathered}
$$

where $y$ is the distance from the point to the near wall. The value of $F_{1}$ is 1 near the wall, so the $k-\omega$ model is used. When the value of $F_{1}$ is 0 away from the wall, the $\mathrm{k}-\varepsilon$ model is adopted. $v_{t}$ is the viscosity of turbulent vortex, which is defined as follows:

$$
v_{t}=\frac{a_{1} k}{\max \left(a_{1} \omega, S F_{2}\right)}
$$

In the formula, $S$ is the invariant of the strain rate, and $F_{2}$ is the second mixed function, which is defined as follows:

$$
F_{2}=\tanh \left[\left[\max \left(\frac{2 \sqrt{k}}{\beta^{*} \omega y}, \frac{500 v}{y^{2} \omega}\right)\right]^{2}\right]
$$

$P_{k}$ is defined as follows:

$$
P_{k}=\min \left(\tau_{i j} \frac{\partial U_{i}}{\partial x_{j}}, 10 \beta^{*} k \omega\right)
$$

where $\beta^{*}=0.09$ and $\sigma_{\omega 2}=0.856$. The other constants are given in [20].

\subsection{Coordinate Systems and Ship Motion Equation}

The motion of the ship is described by two Cartesian coordinates, as shown in Figure 5. The origin fixed to the ship's coordinate system is taken on the ship's center of gravity. The ship has three degrees of freedom: heave, heave and roll. According to the momentum theorem and momentum moment theorem of rigid body dynamics, the equations of motion of the three degrees of freedom in ship space can be expressed as follows:

$$
\begin{aligned}
& m[\dot{u}-v r+w q]=X \\
& m[\dot{w}-u q+v p]=Z \\
& I_{x} \dot{p}+\left[I_{z}-I_{y}\right] q r=K
\end{aligned}
$$

In the above equation, $\mathrm{m}$ represents the mass of the ship. $u, v$ and $w$ are the velocities in the direction of $x, y$ and $z$, respectively. $I_{x}, I_{y}$ and $I_{z}$ are the ship's moment of inertia for 
$X_{S}, Y_{S}$ and $Z_{s}$, respectively. $X$ and $Z$ are the external forces acting on the hull, and $K$ is the external moments acting on the hull. $X_{s}, Y_{s}$ and $Z_{s}$ are the principal axes of inertia of the ship in three directions, respectively.

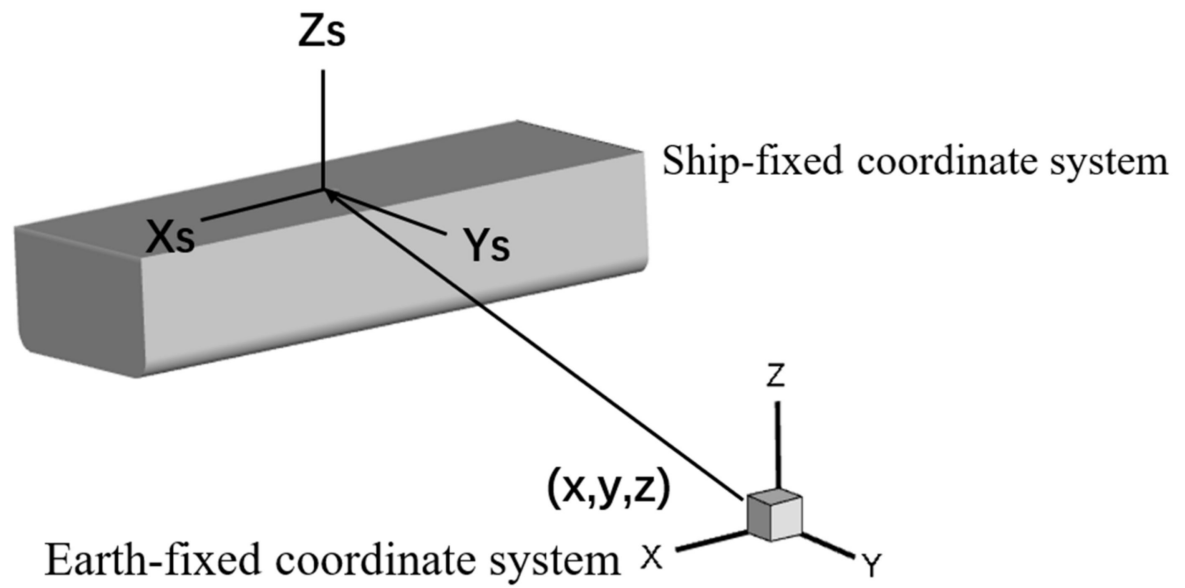

Figure 5. Coordinate system.

\subsection{Level-Set Method}

The level-set method is used to obtain the free surface in the in-house solver, which was originally proposed by Osher [21] and widely used in the numerical simulation [22-24]. In this paper, the in-house CFD solver uses a unidirectional level-set module and ignores the influence of viscosity and air density. Let $\varphi$ be the distance from any point in the flow field to the free surface. Additionally, $\varphi$ is positive in the water and negative in the air, so the free surface is the surface consisting of all points in the flow field $\varphi=0$. The mathematical expression is as follows:

$$
\varphi=\left\{\begin{array}{cr}
<0, & \text { In the water } \\
=0, & \text { In the free surface } \\
>0, & \text { In the air }
\end{array}\right.
$$

The fluid is dynamic in the process of simulation, the free surface can be obtained by solving the supplementary level set function combined with the RANS equation. The level-set equation (Hamilton-Jacobi equation) [25] is defined as follows:

$$
\frac{\partial \phi}{\partial t}+\mathbf{v} \cdot \nabla \phi=0
$$

where $\mathbf{v}$ is the velocity vector of a certain point in the flow field.

\subsection{Computational Domain and Boundary Conditions}

The in-house CFD solver is based on the dynamic overset grid technology. The generation of dynamic overset grids consists of three steps: hole cutting, identification of the interpolation points and the identification of the donor cells. We used the hole mapping method to cut the hole. The donors of interpolation points are found using ADT (an alternative digital tree), while the relationship between the donor points and interpolation points is obtained by the trilinear interpolation method [26]. Reference [27] shows more details about the dynamic overset grid technology we used. Figure 6 shows the surface grid of the ship, and Figure 7 shows the comparison of the grid before and after the overset. 


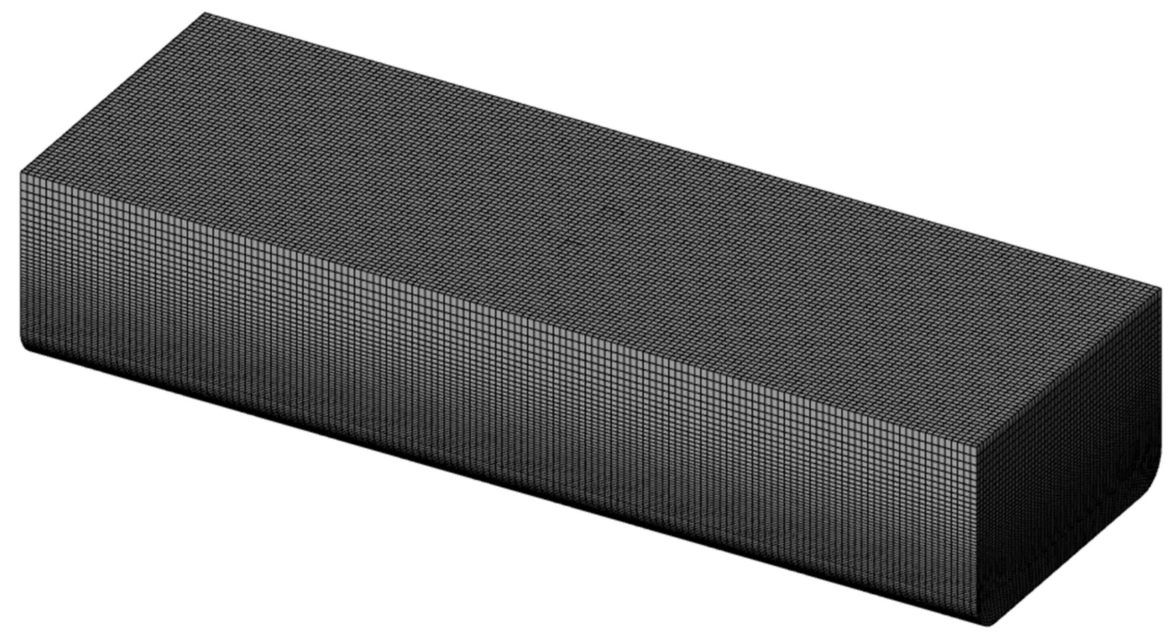

Figure 6. Surface grid of the ship.

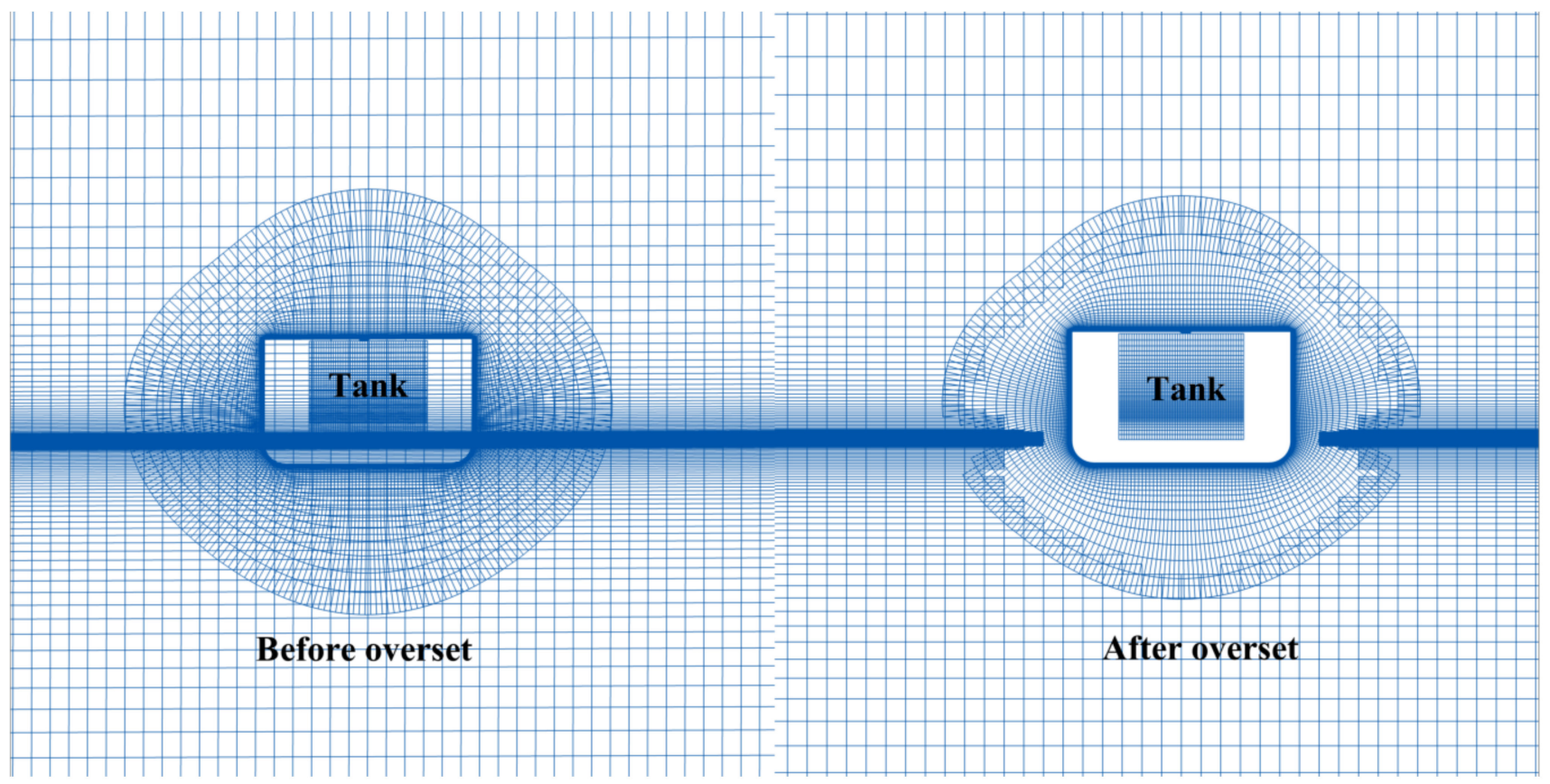

Figure 7. Comparison of the grid before and after overset.

As can be seen from the Figure 7, the grid of the ship, the tank and the computational domain are generated separately before the overset, and the grid of each part is embedded into the background grid. The grid outside the computing domain is excluded from the computation after the overset. The interpolation relationship is then established for the grid of the remaining overset region to solve the whole computing domain. The grid of the computational domain and the hull is refined at the free liquid surface.

The boundary conditions of the computational domain are set as shown in Figure 8. In this study, the velocity of the water particle is given at the entrance of the computational domain, and the flow field is initialized to realize the numerical wave generation. The detailed process of the numerical wave generation technology of the in-house CFD code can be found in reference [7]. 


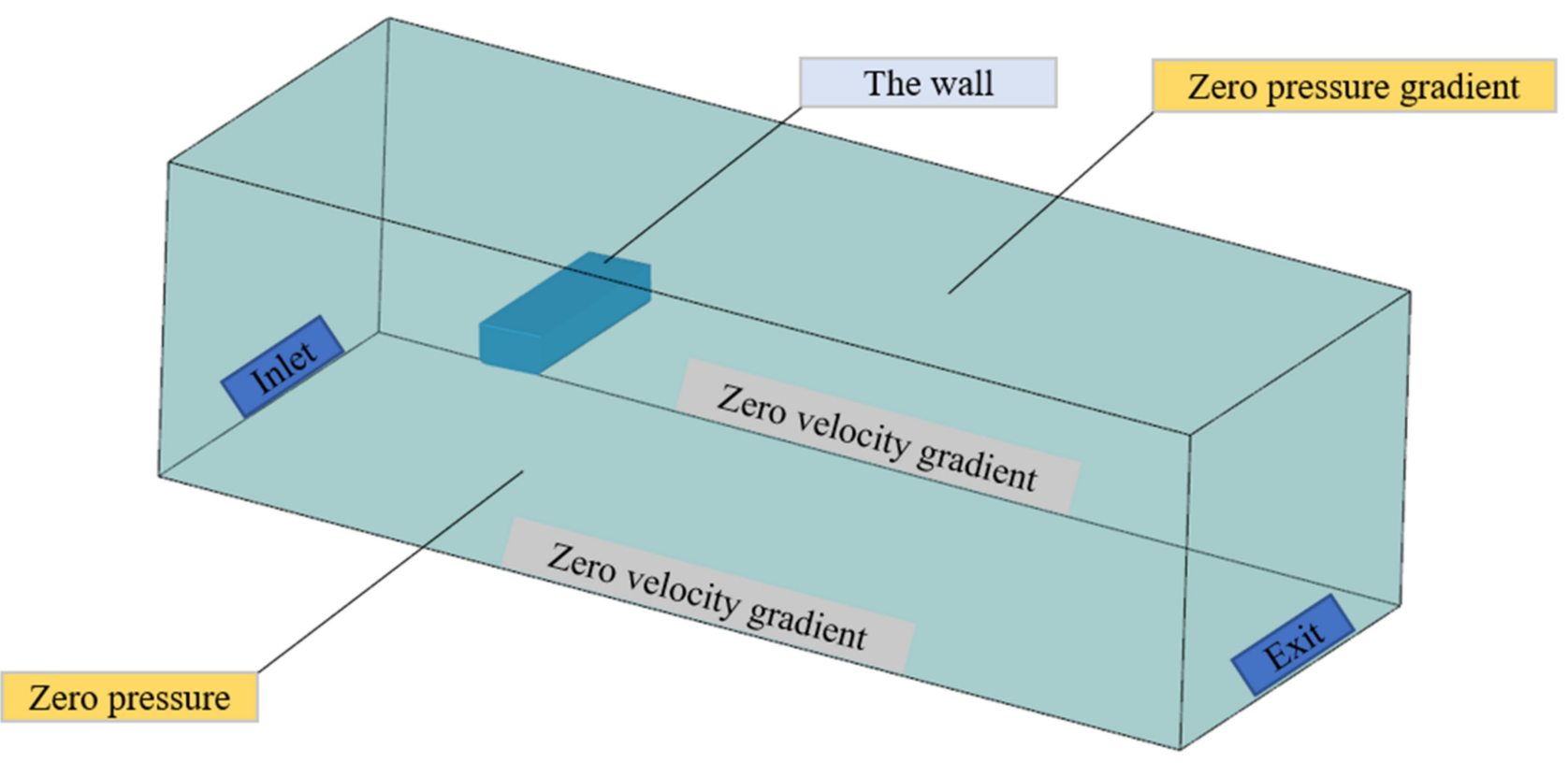

Figure 8. Computational domain and boundary conditions.

\subsection{Grid and Time Step Studies}

To save more computation costs while ensuring sufficient accuracy, grid and time step studies should be conducted. On three grids of different fitness levels, we computed the characteristics of the motion and force of the ship in a regular beam wave. In the simulation, the wavelength ratio is 0.787 , the size of the tank is $0.57 \times 0.57 \times 0.5 \mathrm{~m}$ and the height of the liquid in the tank is $0.1 \mathrm{~m}$. The grid number of the coarse grid 1 is 3.29 million. For the medium grid 2, comprising a volume of 6.71 million grids, we increased refinement by a factor of $\sqrt[3]{2}$ over the length, width and height of the computational model. For the fine grid 3, comprising a volume of 13.53 million grids, we increased refinement again by a factor of $\sqrt[3]{2}$ over each direction. In order to ensure that the time interval, $\Delta t$, has no influence on the simulation results, we set the same time interval, $\Delta \mathrm{t}$, of $0.006 \mathrm{~s}$ for these three grids.

Figures 9 and 10 compare the roll angle of the ship. The dimensionless roll angle, $\tilde{\theta}$, is computed as follows:

$$
\tilde{\theta}=\theta / A K
$$

where $A$ is the amplitude of the wave, and $K$ is the wave number. All the roll angles in the following paper represent dimensionless roll angles, $\tilde{\theta}$. In Figure 9, orange dashed, black solid and blue dashed lines identify the roll angle of the ship obtained on grids 1, 2 and 3, respectively. In Figure 10, orange dashed, black solid and blue dashed lines identify the roll angle of the ship obtained from simulations with a decreasing time interval, $\Delta t$, of $0.012 \mathrm{~s}, 0.006 \mathrm{~s}$ and $0.003 \mathrm{~s}$, respectively, and all computed on grid 2. All the computations are carried out on the Guangzhou supercomputer called Tianhe-2. 


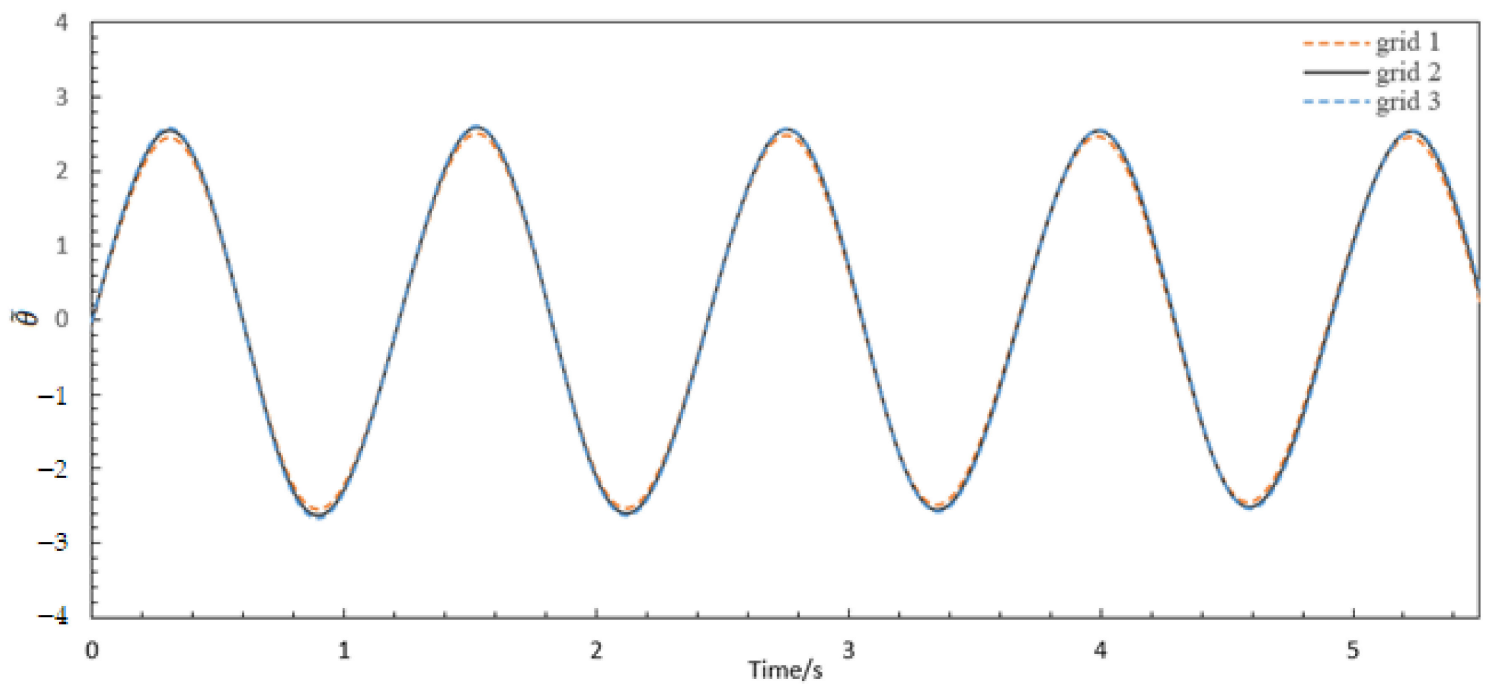

Figure 9. Time histories of $\widetilde{\theta}$ of the ship obtained on grids 1,2 and 3.

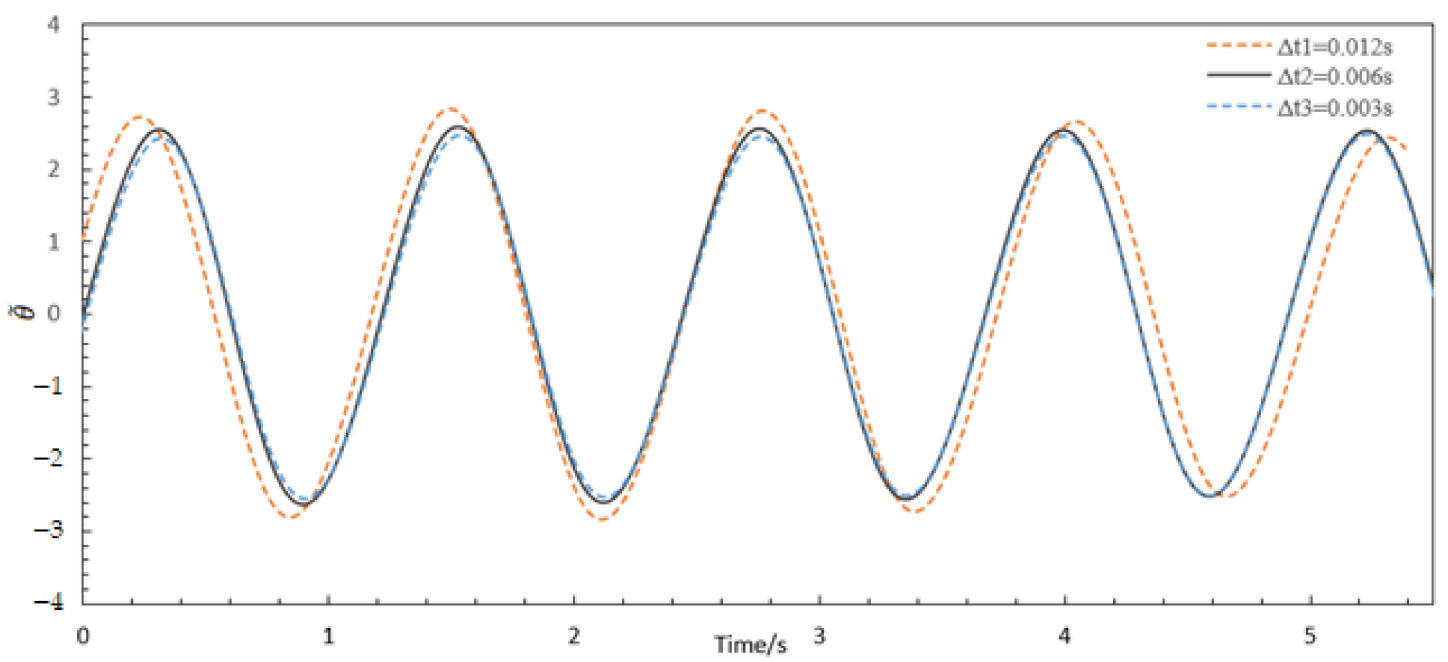

Figure 10. Time histories of $\widetilde{\theta}$ of the ship obtained on grid 2 from simulations with three different time steps.

It can be seen from Figure 9 that the computation results obtained from grid 2 and grid 3 are very close, and the computation results obtained from grid 2 and grid 3 are quite different from those obtained from grid 1. The roll angle amplitudes of grid 1, grid 2 and grid 3 are 2.475, 2.579 and 2.593, respectively. The amplitude deviation of the roll angle between grid 1 and grid 2 is $\varepsilon 12=0.104$. The amplitude deviation of the roll angle between grid 2 and grid 3 is $\varepsilon 23=0.014$. We can obtain the convergence ratio of $\mathrm{R}=\varepsilon 32 / \varepsilon 21=0.135$ [28]. Since the convergence ratio is between 0 and 1 , it shows that the spatial discretization is monotonous, so grid 2 is fine enough to produce a convergence prediction. Table 4 shows the related parameters of three different grids.

Table 4. Related parameters of three different grids.

\begin{tabular}{cccc}
\hline Grid Case & Grid Number & The Amplitude of the $\tilde{\theta}$ & Error (Middle\%) \\
\hline Grid 1 & 3.29 million & 2.475 & -4.03 \\
Grid 2 & 6.71 million & 2.579 & - \\
Grid 3 & 13.53 million & 2.593 & 0.54 \\
\hline
\end{tabular}


The working conditions corresponding to the three time intervals in Figure 10 are computed using grid 2. The internal time for the first computation is set to $0.012 \mathrm{~s}$. The internal time of the second and third computations are $0.006 \mathrm{~s}$ and $0.003 \mathrm{~s}$, respectively. Figure 10 show that the results obtained from $\Delta \mathrm{t} 2$ and $\Delta \mathrm{t} 3$ are very close, and the results obtained from $\Delta \mathrm{t} 1$ are quite different. The roll angle amplitudes of $\Delta \mathrm{t} 1, \Delta \mathrm{t} 2$ and $\Delta \mathrm{t} 3$ are $2.803,2.579$ and 2.511 , respectively. The amplitude deviation of the roll angle between $\Delta \mathrm{t} 1$ and $\Delta \mathrm{t} 2$ is $\varepsilon 12=-0.224$. The amplitude deviation of the roll angle between $\Delta \mathrm{t} 2$ and $\Delta \mathrm{t} 3$ is $\varepsilon 23=-0.068$. Thus, the convergence ratio of $\mathrm{R}=\varepsilon 23 / \varepsilon 12=0.303$ [23]. The convergence ratio is between 0 and 1 , and it shows that the spatial discretization is monotonous, so $\Delta \mathrm{t} 2$ has sufficient accuracy to make the computation convergent. Table 5 shows the related parameters of three different time steps.

Table 5. Related parameters of three different time steps.

\begin{tabular}{cccc}
\hline Time Case & $\Delta \mathrm{t}$ & The Amplitude of the $\tilde{\theta}$ & Error (Middle\%) \\
\hline$\Delta \mathrm{t} 1$ & $0.012 \mathrm{~s}$ & 2.803 & 8.69 \\
$\Delta \mathrm{t} 2$ & $0.006 \mathrm{~s}$ & 2.579 & - \\
$\Delta \mathrm{t} 3$ & $0.003 \mathrm{~s}$ & 2.511 & -2.64 \\
\hline
\end{tabular}

Moreover, we have calculated the Grid Convergence Index (GCI) according to the method in [29]. According to this method, a representative grid size $h$ is defined. For three-dimensional calculations:

$$
h=\left[\frac{1}{N} \sum_{i=1}^{N}\left(\Delta V_{i}\right)\right]^{\frac{1}{3}}
$$

where $\Delta V_{i}$ is the volume of the cell, and $N$ is the total number of cells used for the computations.

$N_{1}, N_{2}$ and $N_{3}$, represent the grid number of fine, medium and coarse grids, respectively. Let $h_{1}<h_{2}<h_{3}$ and $r_{21}=h_{2} / h_{1}, r_{32}=h_{3} / h_{2}$, and calculate the apparent order $p$ of the method using the expression:

$$
\begin{gathered}
p=\frac{1}{\ln \left(r_{21}\right)}|\ln | \varepsilon_{32} / \varepsilon_{21}|+q(p)| \\
q(p)=\ln \left(\frac{r_{21}^{p}-s}{r_{32}^{p}-s}\right) \\
s=1 * \operatorname{sgn}\left(\varepsilon_{32} / \varepsilon_{21}\right)
\end{gathered}
$$

Calculate the extrapolated values from

$$
\varnothing_{\text {ext }}^{21}=\left(r_{21}^{p} \varnothing_{1}-\varnothing_{2}\right) /\left(r_{21}^{p}-1\right)
$$

Calculate and report the following error estimate, along with the apparent order $p$. In the approximate relative error:

$$
e_{a}^{21}=\left|\frac{\varnothing_{1}-\varnothing_{2}}{\varnothing_{1}}\right|
$$

In the approximate relative error:

$$
e_{\text {ext }}^{21}=\left|\frac{\varnothing_{\text {ext }}^{21}-\varnothing_{1}}{\varnothing_{e x t}^{21}}\right|
$$


In the fine-grid convergence index:

$$
G C I_{\text {fine }}^{21}=\frac{1.25 e_{a}^{21}}{r_{21}^{p}-1}
$$

Table 6 illustrates this calculation procedure for three selected grids. According to Table 6, the numerical uncertainty in the fine-grid solution for the reattachment length should be reported as $0.105 \%$.

Table 6. Calculations of discretization error.

\begin{tabular}{cc}
\hline & $\varnothing$ Is the Amplitude of the $\tilde{\theta}$ \\
\hline$N_{1}, N_{2}, N_{3}$, & $13.53 \mathrm{M}, 6.71 \mathrm{M}, 3.29 \mathrm{M}$ \\
$\varnothing_{1}$ & 2.593 \\
$\varnothing_{2}$ & 2.579 \\
$\varnothing_{3}$ & 2.475 \\
$p$ & 8.677 \\
$\varnothing_{\text {ext }}^{21}$ & 2.595 \\
$e_{a}^{21}$ & $0.540 \%$ \\
$e_{x+t}^{21}$ & $0.084 \%$ \\
$G C I_{\text {fine }}^{21}$ & $0.105 \%$ \\
\hline
\end{tabular}

\section{Result and Discussion}

The motions and forces of the ship with/without a tank in beam waves were calculated using the in-house CFD solver. In the numerical simulation, three degrees-of-freedom motions of the components sway, roll and heave were considered. In this paper, the effects of fill levels inside the tank, tank length and wave steepness on ship motion are studied by comparing the different simulation results and experimental results.

To study the influence of liquid filling on the ship's motion, three different heights of liquid in the tank, including $0.1 \mathrm{~m}, 0.2 \mathrm{~m}$ and $0.3 \mathrm{~m}$, were set up. Moreover, two tank sizes were set up to study the effect of the tank on the ship's motion and forces. In the simulation and experiment, the hull would roll, sway and heave under the action of regular waves.

\subsection{Validation}

Firstly, we have verified the numerical model. The accuracy of the numerical model was verified by comparing the roll motion and heave motion of the ship as well as the pressure on the tank wall.

Figure 11 shows the curves of the roll angle of the ship by the CFD method and experiments. It can be seen that the variation curves of the roll angle obtained by the CFD method and EFD method are in good agreement with each other, and the errors in the amplitude and phase of the roll angle are small. In order to further verify the numerical method, Figure 12 compares the CFD and EFD results of the ship's roll angle amplitudes without a tank under the action of regular waves with different wavelength ratios. It can be seen from Figure 12 that the difference between CFD and EFD is acceptable, and the law of the variation of roll angle amplitude with wavelength is consistent between CFD and EFD results. 


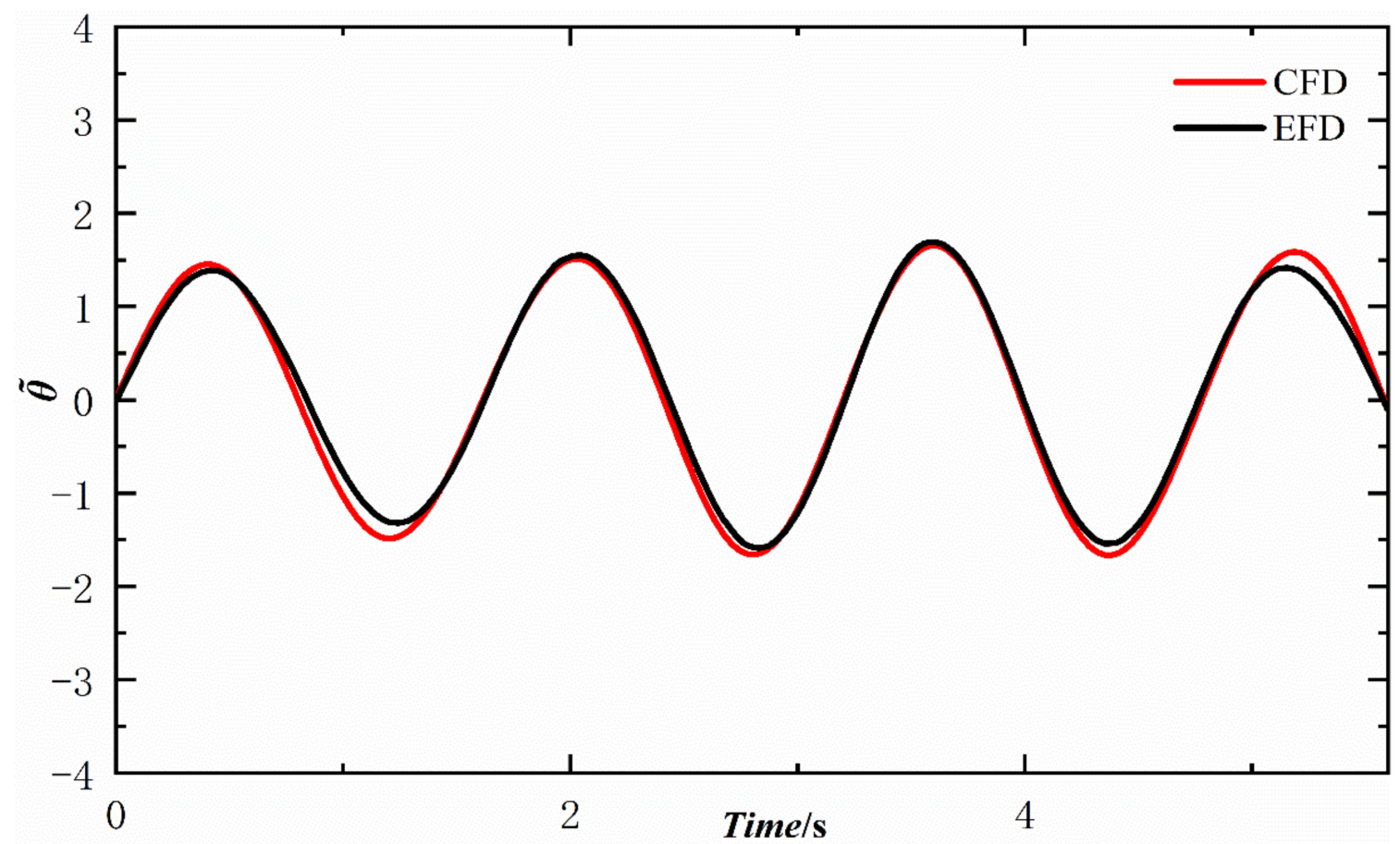

Figure 11. Comparison of the roll angle of ship with tank between CFD and EFD at a wavelength ratio of 1.334 and a tank length of $1.17 \mathrm{~m}$.

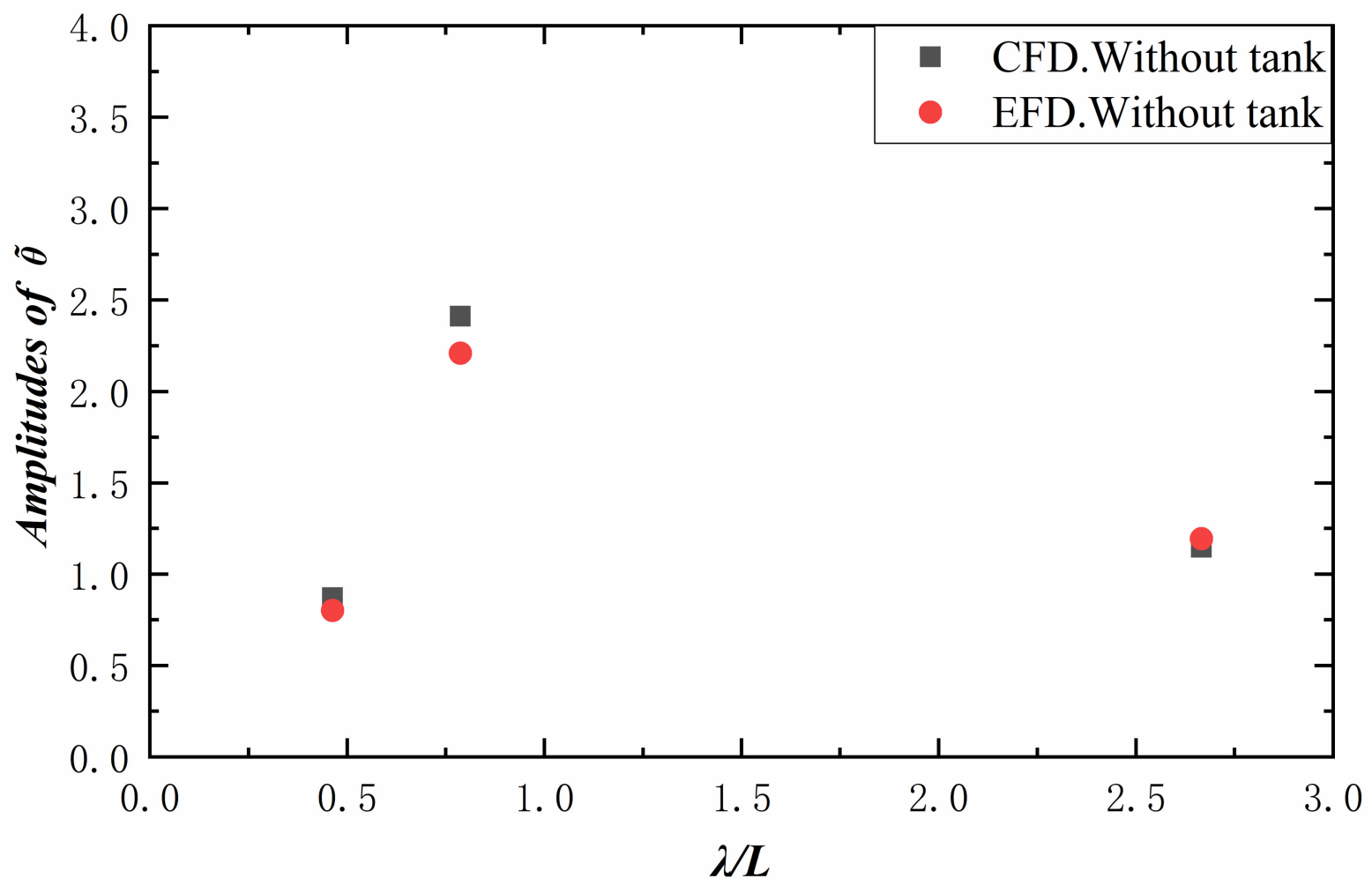

Figure 12. For the ship in beam waves, comparative roll amplitudes by CFD and EFD without accounting for sloshing in tanks.

\subsection{Effect of the Parameters of the Tank}

In this paper, the coupling motion between the hull and the liquid in the tank is analyzed by the result of the CFD simulation and experiment. The effects of the liquid 
height and the length of the tank on the ship motion are studied. In addition, the forces and motions of the ship in regular beam waves with different wavelength ratios are also studied.

\subsubsection{Effect of Fill Levels inside the Tank}

In order to determine the influence of the liquid level height in the tank on the motion of the ship in beam waves, the following three working conditions were set:

1. The ship is without the tank;

2. The ship with a tank of $0.57 \times 0.57 \times 0.5 \mathrm{~m}$, and the liquid level height in the tank is $0.1 \mathrm{~m}$;

3. The ship with a tank of $0.57 \times 0.57 \times 0.5 \mathrm{~m}$, and the liquid level height in the tank is $0.2 \mathrm{~m}$;

4. The ship with a tank of $0.57 \times 0.57 \times 0.5 \mathrm{~m}$, and the liquid level height in the tank is $0.3 \mathrm{~m}$.

Figure 13 depicts the dimensionless rolling amplitude of the ship under the above three working conditions in different incident waves. The results of the ship's rolling amplitude under different working conditions are graphically represented by different colors and shapes.

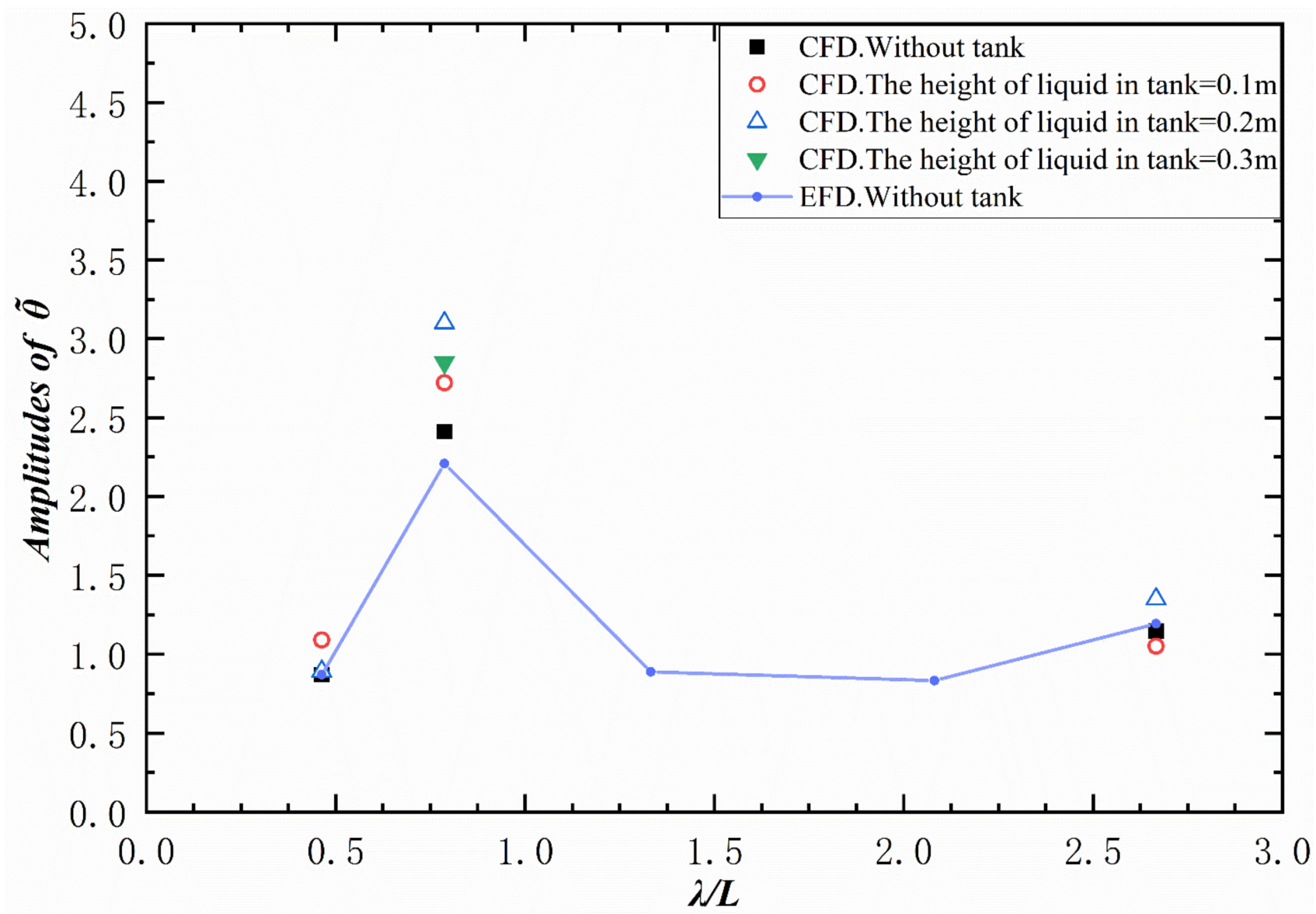

Figure 13. For the ship in beam waves, comparative roll amplitudes of the ship obtained from numerical simulations and experiment with and without a tank.

From the results of EFD, it can be seen that the variation trend of the ship roll amplitude with the wavelength ratio increases at first and then decreases, and the maximum roll amplitude is obtained when the wavelength ratio is 0.787. The CFD results show that tank sloshing has influence on ship rolling, and the effect is different at different wavelength ratios. 
When the wavelength ratio is 0.436 , the amplitude of the ship's rolling angle increases when the liquid height in the tank is $0.1 \mathrm{~m}$. When the liquid height in the tank is $0.2 \mathrm{~m}$, the tank sloshing has little effect on the rolling motion of the ship. In this condition, wave force plays the most important role in ship motion, and the force caused by liquid in the tank is very small.

When the wavelength ratio is 0.787 , the wave frequency is close to the natural frequency of the ship's rolling. Therefore, the wave resonates with the ship, and the amplitude of the rolling angle reaches its maximum in this condition. As can be seen from Figure 13, tank sloshing would promote the rolling motion of the ship in this condition. When the liquid height in the tank is $0.2 \mathrm{~m}$, tank sloshing increases the amplitude of the ship's roll angle by $28.6 \%$. When the liquid height is $0.1 \mathrm{~m}$, the amplitude of the ship roll angle increase by $12.9 \%$.

To physically interpret the simulation results, the moments of the ship and the tank are analyzed later.

Figure 14 shows the rolling moment of the ship and the tank when the wavelength ratio is 0.787 . From Figure 14, it can be seen that when the liquid height in the tank is $0.1 \mathrm{~m}$, the phase difference between the two curves is close to $\pi / 2$, so the effect of the tank sloshing on the ship is small.

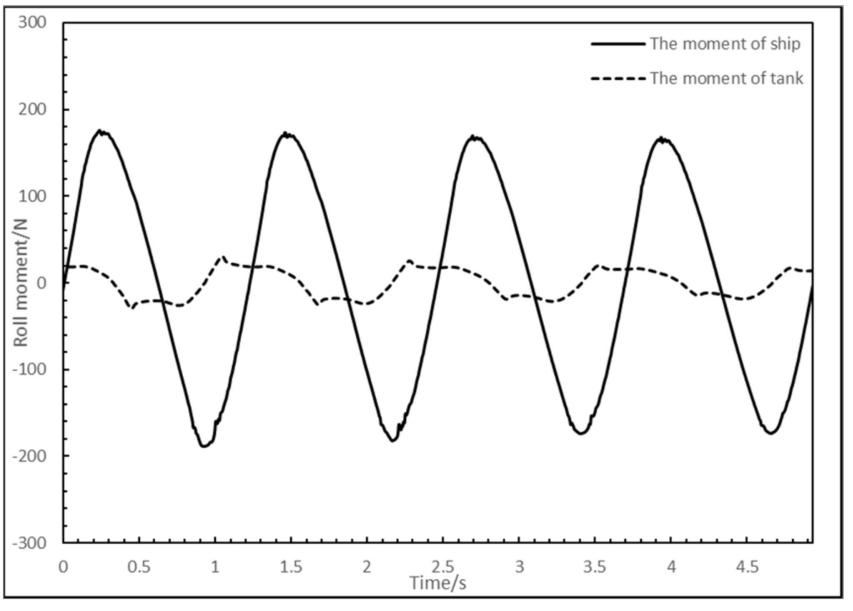

(a)

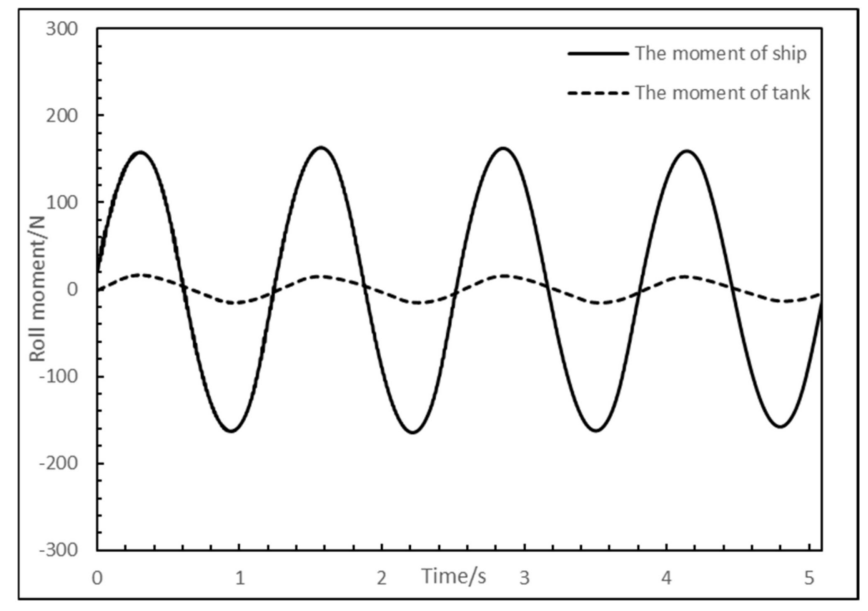

(b)

Figure 14. Roll moment of the ship and tank when the wavelength ratio is 0.787 (a) The height of liquid in the tank is $0.1 \mathrm{~m}$; (b) The height of liquid in the tank is $0.2 \mathrm{~m}$.

When the liquid height in the tank is $0.2 \mathrm{~m}$, the phase difference between the two curves is close to 0 , so tank sloshing would promote the rolling motion of the ship. The force on the ship is mainly the wave force in this condition. In the long wave with a wavelength ratio of 2.667, tank sloshing would reduce the rolling amplitude of the ship when the height of liquid in the tank is $0.1 \mathrm{~m}$, and the amplitude of the ship's roll angle is $8.3 \%$ lower than that without tank sloshing.

Figure 15 shows the rolling moment of the ship and tank (the height of liquid in the tank is $0.1 \mathrm{~m}$ ) when the wavelength ratio is 0.463 . 


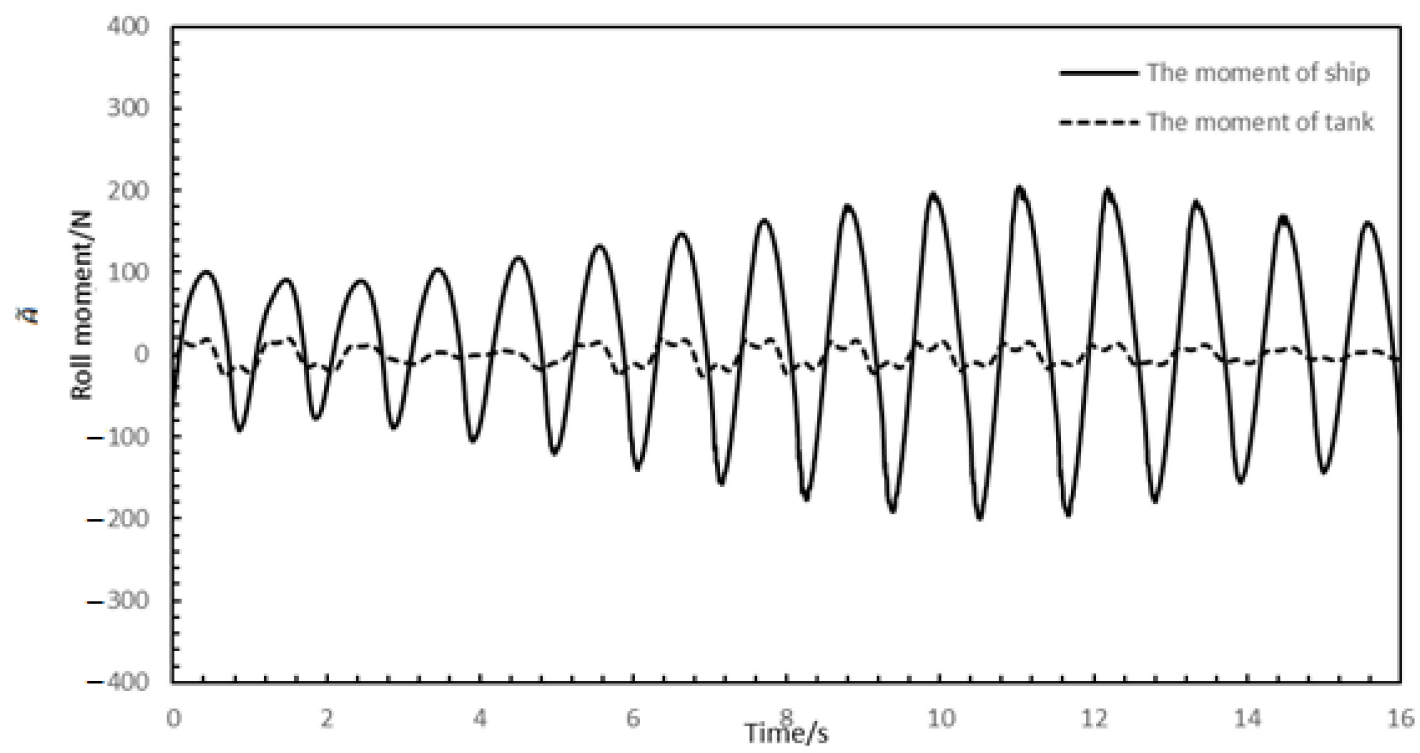

Figure 15. Rolling moment of the ship and tank (the height of liquid in the tank is $0.1 \mathrm{~m}$ ) when the wavelength ratio is 0.463 .

As can be seen in Figure 15, the phase difference between the moment curve of the tank and that of the ship is small, so the liquid sloshing in the tank would increase the rolling amplitude of the ship. The tank moment curve is not smooth and fluctuates at the peak in each cycle. The reason for the above phenomenon is the sloshing impact on the tank bulkhead.

Through the above research, we can draw the conclusion that the additional disturbance moment caused by tank sloshing would not change the period and phase of the ship rolling curve, but the phase difference between the wave disturbance moment and the tank sloshing additional disturbance moment would change the amplitude of ship rolling.

As mentioned earlier, we have monitored the pressure at several points in the bulkhead during the experiment and simulation. Figure 16 shows the pressure amplitudes of these points under different working conditions.

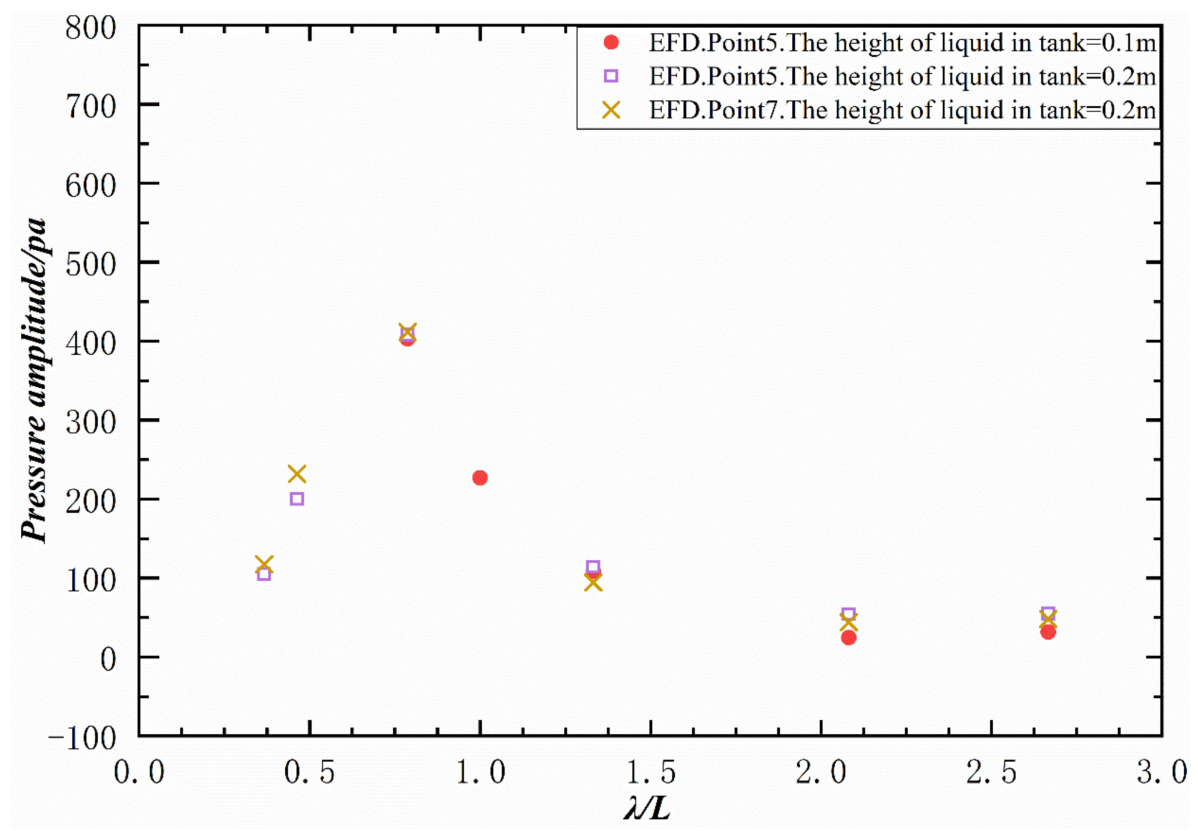

Figure 16. The pressure amplitude of two points on the bulkhead. 
From Figure 16, it can be seen that the trend of the pressure amplitude of the two points with the wavelength ratio is the same as that of the ship rolling amplitude in Figure 13. The pressure amplitude reaches the maximum when the wavelength ratio is 0.787 because the wave resonates with the ship. We can conclude that changing the liquid height in the tank has little influence on the pressure amplitude of the same point. In addition, when the height of liquid in the tank is the same, the pressure amplitudes of point 5 and point 7 are very close.

Figure 17 shows the heave amplitude of the ship in different conditions.

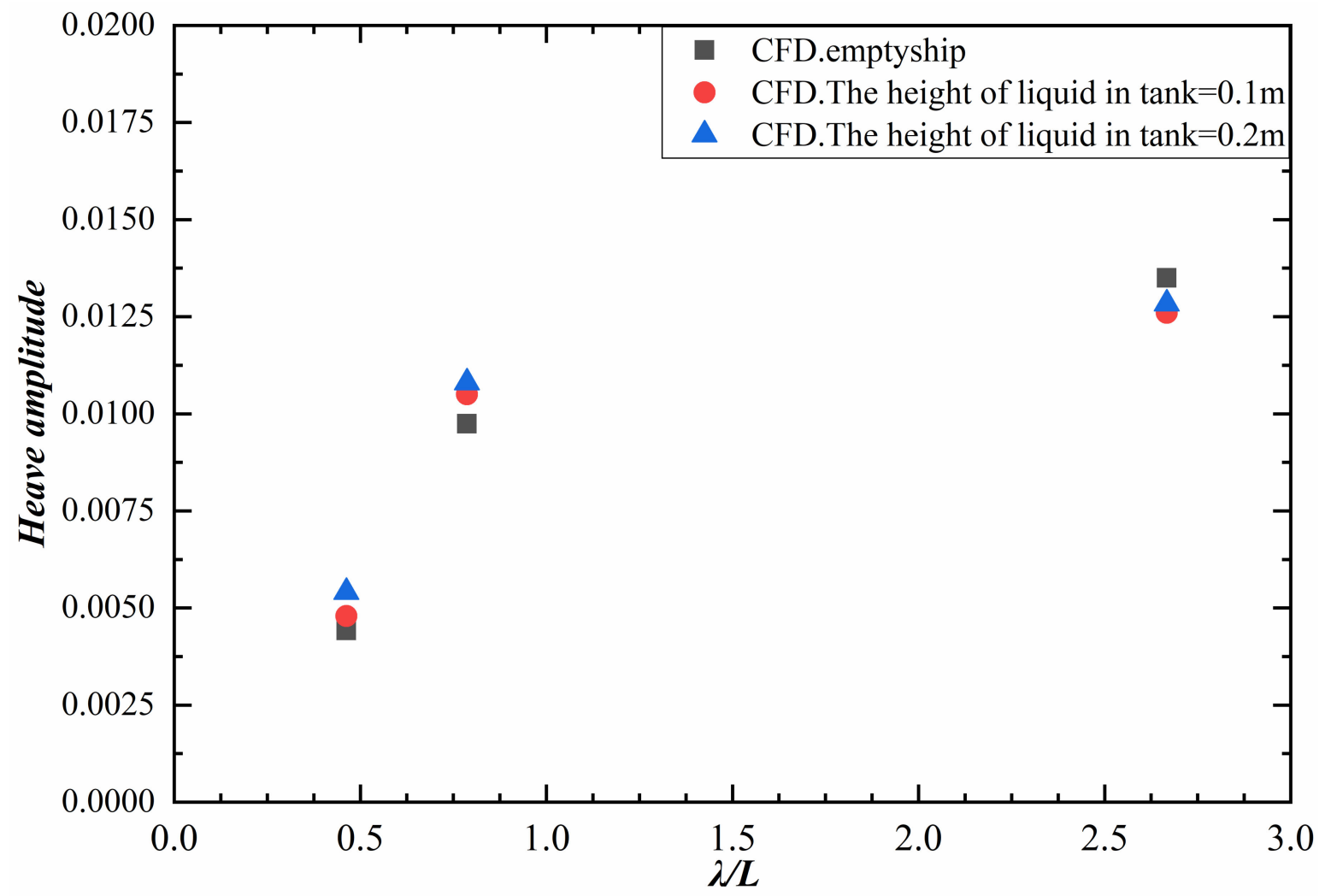

Figure 17. The heave amplitude of the ship.

As can be seen from Figure 17, at the wavelength ratio of 0.463 and 0.787 , heave motions increased slightly, while at the wavelength of 2.667 , heave motions decreased slightly.

Figure 18 shows the time histories of the force in $z$ direction for the ship in beam waves at $\lambda / \mathrm{L}=0.787$ with a liquid height of $0.1 \mathrm{~m}$. It can be seen from Figure 18 that the $\mathrm{Fz}$ of the tank is small compared to the Fz of the ship. Thus, the sloshing has little influence on the heave motion of the ship. The result is similar to research by a hybrid method [30] for a ship's response coupled with sloshing. 


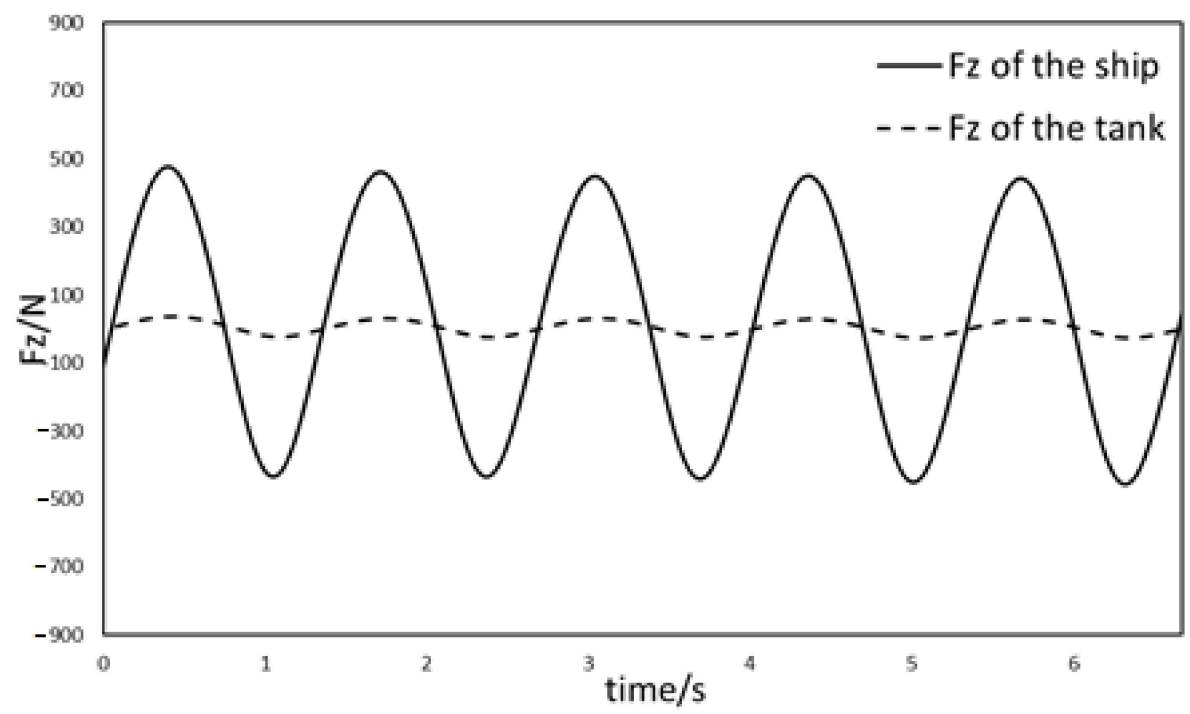

Figure 18. For the ship in beam waves at $\lambda / L=0.787$, time histories of the force in $\mathrm{z}$ direction.

Figure 19 shows the wave pattern in four different times in the numerical simulation.

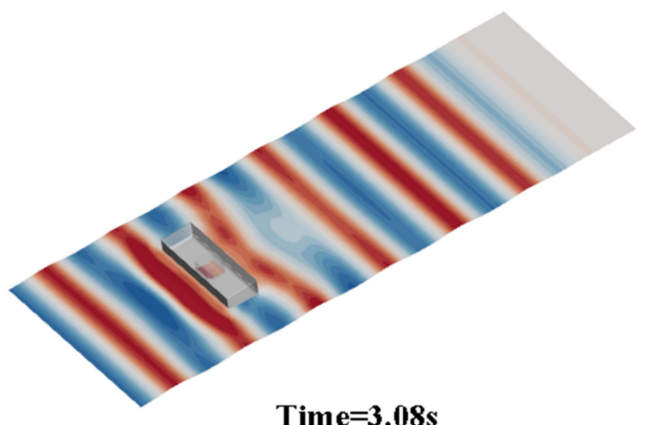

Time $=3.08 \mathrm{~s}$

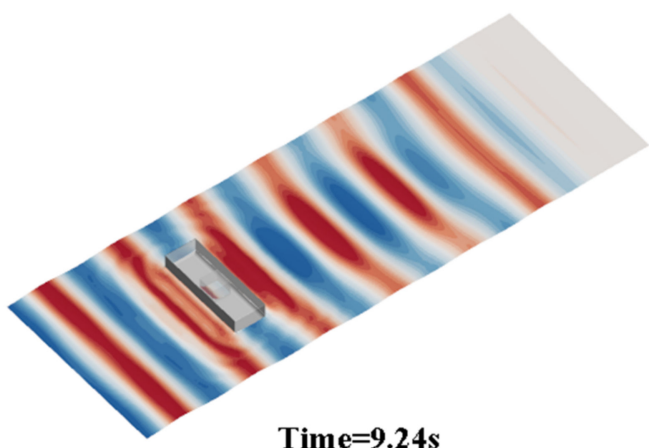

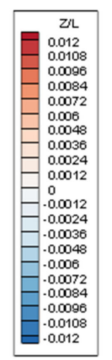

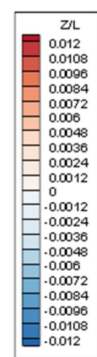

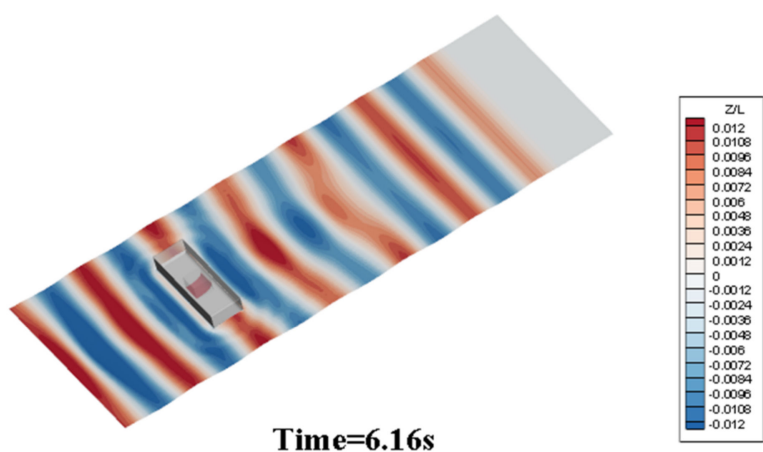

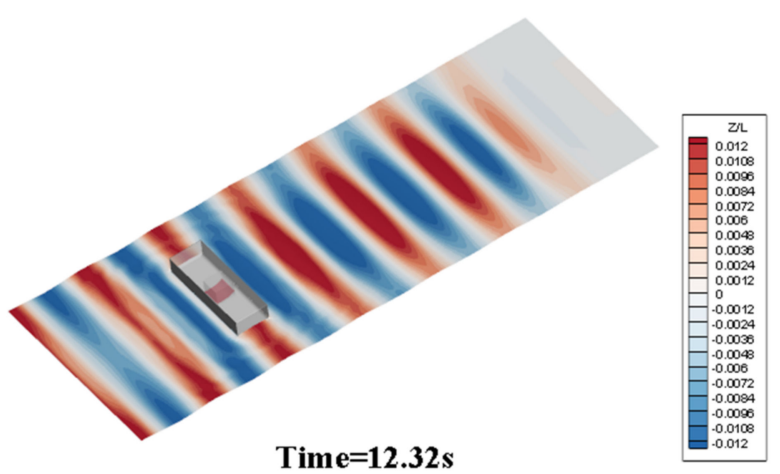

Figure 19. The wave pattern in different time.

As can be seen from Figure 19, when the time is $3.08 \mathrm{~s}$, the ship motion has little influence on the wave pattern. When the time is $6.16 \mathrm{~s}$, the wave pattern in the range of two wavelengths on the side of the ship changes due to the motion of the ship. After $9.24 \mathrm{~s}$, the wave pattern between the ship and the pressure outlet is not a regular sine. The reason for the above is the interference of the ship's motion-induced ship-making by the incident wave.

For the ship in regular beam waves of a length ratio of $\lambda / L=0.787$, our simulation results show that the position of the ship is cause by waves and the surface elevation is caused by the sloshing in the tank. Figures 20-22 show these ship positions and surface 
elevations in the tank at the four representative time steps of $\mathrm{t}=0, \mathrm{t}=1 / 4 \times \mathrm{T}, \mathrm{t}=1 / 2 \times \mathrm{T}$ and $\mathrm{t}=3 / 4 \times \mathrm{T}$ obtained over one typical wave period, $\mathrm{T}$.

When the height of the liquid in the tank is $0.1 \mathrm{~m}$, at time $=0$, the ship is about to roll to the left while the internal sloshing flow heads upwards on the right side of the tank wall, while at time $=1 / 2 \times \mathrm{T}$, the ship is about to roll to the right while the internal sloshing flow heads upwards on the left side of the tank wall. At time $=1 / 4 \times \mathrm{T}$ and $3 / 4 \times \mathrm{T}$, the ship tilts to the maximum angle to the left and right, respectively, and the maximum height of the internal sloshing liquid appears in the middle of the tank.

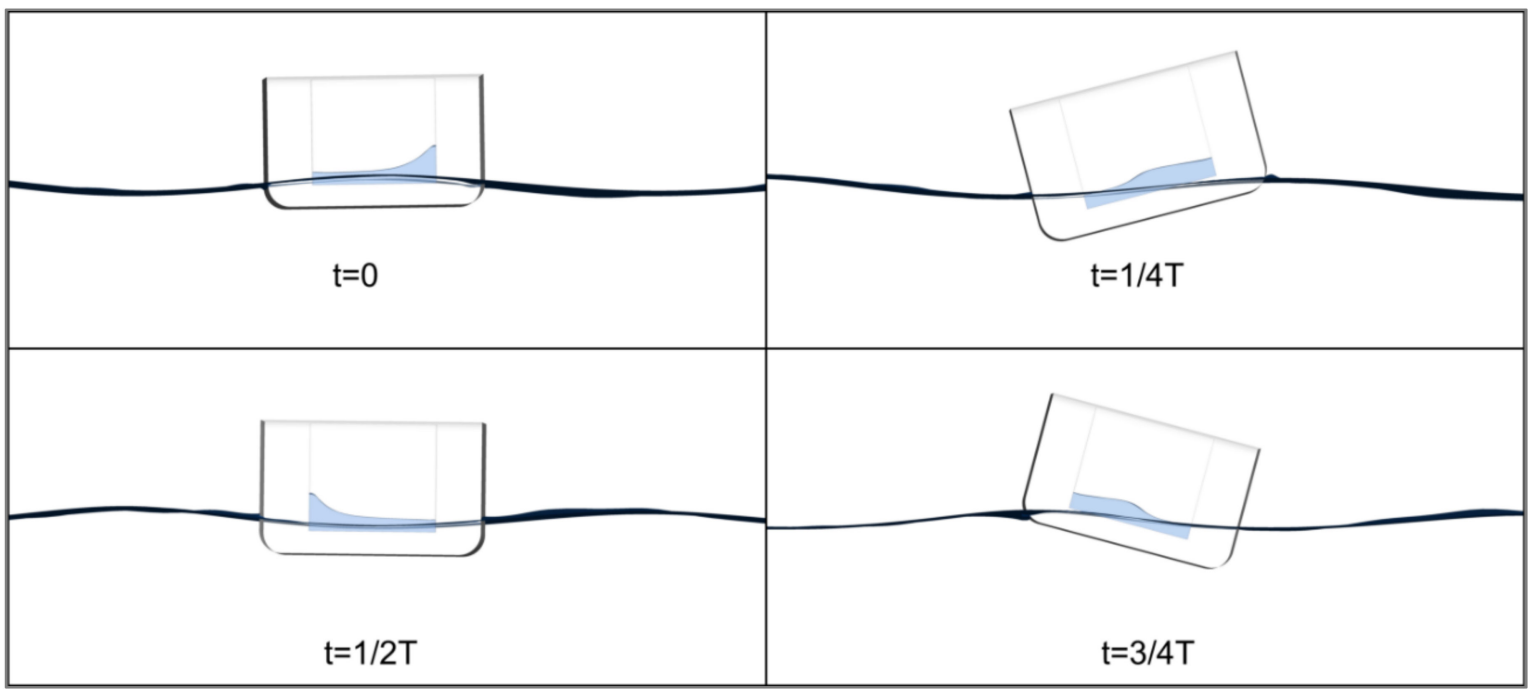

Figure 20. For the ship in beam waves at $\lambda / L=0.787$ with the height of liquid in the tank at $0.1 \mathrm{~m}$, wave-induced ship positions and sloshing-induced surface elevations inside the tank at time steps of $\mathrm{t}=0, \mathrm{t}=1 / 4 \times \mathrm{T}, \mathrm{t}=1 / 2 \times \mathrm{T}$ and $\mathrm{t}=3 / 4 \times \mathrm{T}$.

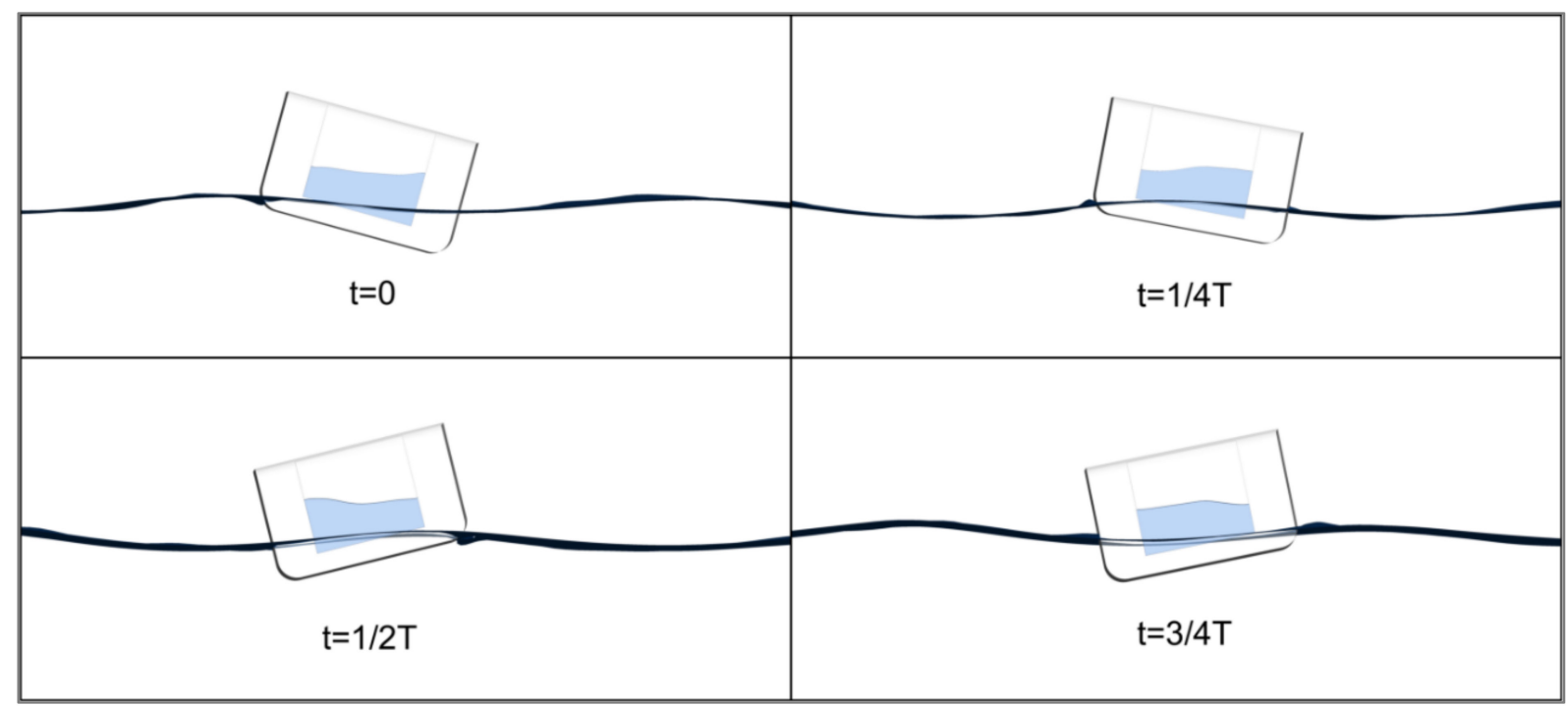

Figure 21. For the ship in beam waves at $\lambda / L=0.787$ with the height of the liquid in the tank at $0.2 \mathrm{~m}$, wave-induced ship positions and sloshing-induced surface elevations inside the tank at time steps of $\mathrm{t}=0, \mathrm{t}=1 / 4 \times \mathrm{T}, \mathrm{t}=1 / 2 \times \mathrm{T}$ and $\mathrm{t}=3 / 4 \times \mathrm{T}$. 


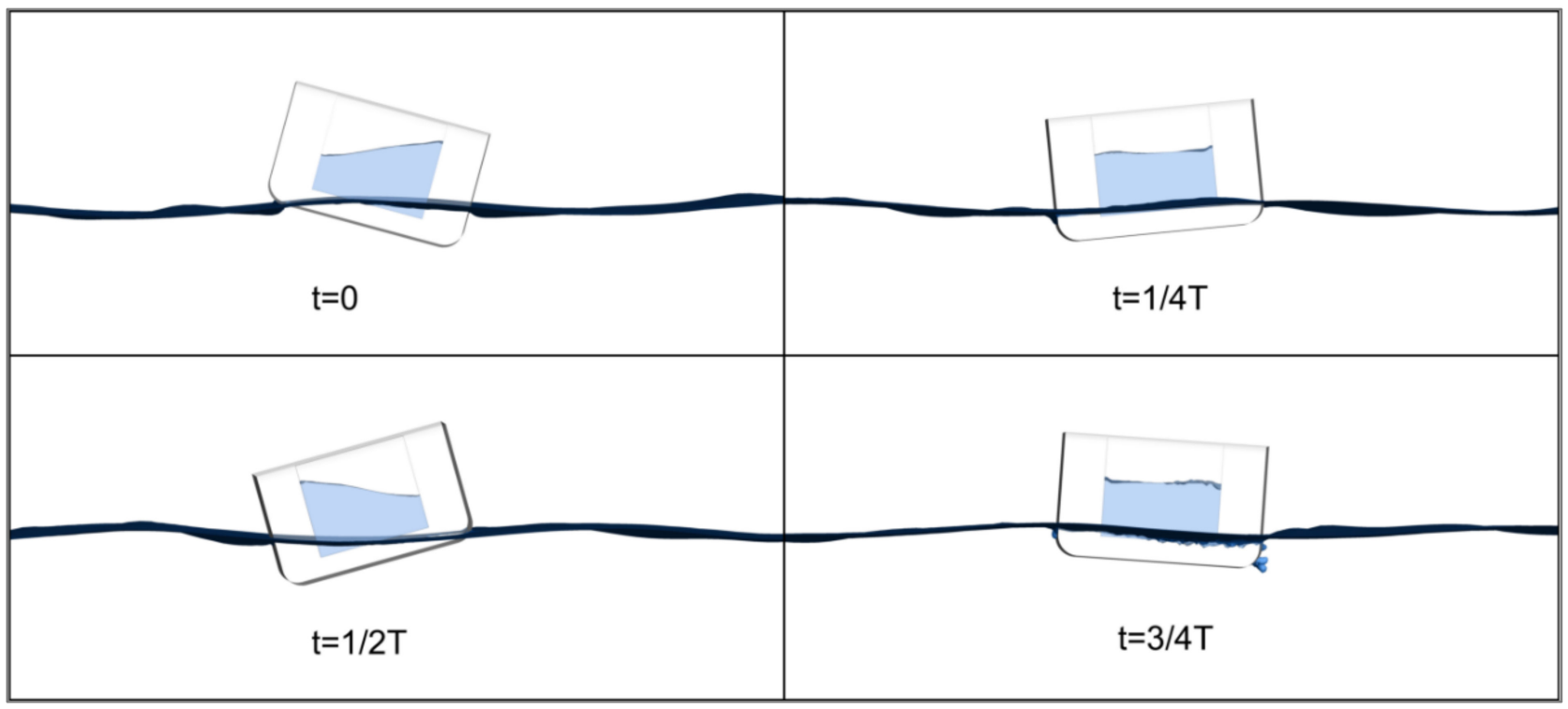

Figure 22. For the ship in beam waves at $\lambda / L=0.787$ with the height of the liquid in the tank at $0.3 \mathrm{~m}$, wave-induced ship positions and sloshing-induced surface elevations inside the tank at time steps of $\mathrm{t}=0, \mathrm{t}=1 / 4 \times \mathrm{T}, \mathrm{t}=1 / 2 \times \mathrm{T}$, and $\mathrm{t}=3 / 4 \times \mathrm{T}$.

When the height of the liquid in the tank is $0.2 \mathrm{~m}$, at time $=0$, the ship rolls to the right while the internal sloshing flow heads upwards on the right side of the tank wall, while at time $=1 / 2 \times \mathrm{T}$, the ship rolls to the right while the internal sloshing flow heads upwards on the left side of the tank wall. At time $=1 / 4 \times \mathrm{T}$ and $3 / 4 \times \mathrm{T}$, the sloshing of the internal liquid is different from that in Figure 19.

When the height of the liquid in the tank is $0.3 \mathrm{~m}$, at time $=0$, the ship rolls to the right while the internal sloshing flow heads upwards on the right side of the tank wall, while at time $=1 / 2 \times \mathrm{T}$, the ship rolls to the right while the internal sloshing flow heads upwards on the left side of the tank wall. At time $=1 / 4 \times \mathrm{T}$ and $3 / 4 \times \mathrm{T}$, the sloshing of the internal liquid is also different from that in Figure 19. Due to the high liquid level in the tank, the liquid in the tank will hit the lid at the top of the tank during sloshing, so serious wave breaking could occur. According to the above, when the height of the internal sloshing liquid is different, the sloshing law is different in one wave period.

\subsubsection{Effect of Tank Length}

In order to obtain the influence of the liquid height in the tank on the motion of the ship in beam waves, the following three working conditions are set:

1. The ship is without the tank;

2. The ship with a tank of $0.57 \times 0.57 \times 0.5 \mathrm{~m}$, and the liquid level height in the tank is $0.1 \mathrm{~m}$;

3. The ship with a tank of $0.57 \times 1.17 \times 0.5 \mathrm{~m}$, and the liquid level height in the tank is $0.1 \mathrm{~m}$.

As can be seen from Figure 23, the tank sloshing would increase the amplitude of the ship's roll angle at the wavelength ratio of 0.436 . Moreover, the amplitude of the ship's roll angle increases with the increase in the length of the tank. When the length of the tank is $1.17 \mathrm{~m}$, tank sloshing increases the amplitude of the ship's roll angle by $43.6 \%$. 


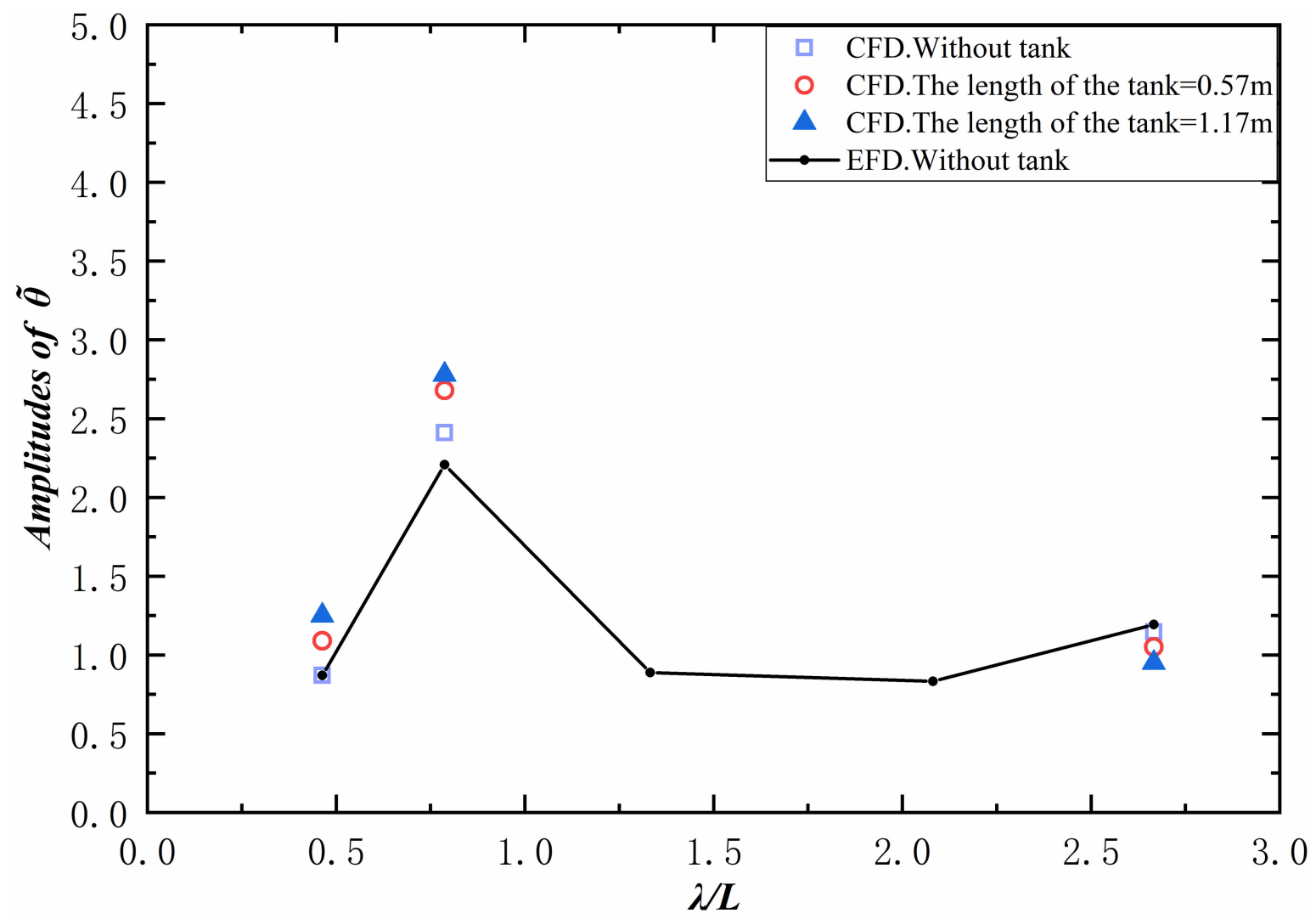

Figure 23. For the ship in beam waves, comparative roll amplitudes of the ship obtained from numerical simulations and experiment with and without tank.

When the wavelength ratio is 0.787 , the tank sloshing would also increase the amplitude of the ship's roll angle slightly. The amplitude of the ship's roll angle increases with the increase in the length of the tank.

In the long wave with a wavelength ratio of 2.667, the tank sloshing has little influence on the amplitude of the ship's roll angle when the tank length is $0.57 \mathrm{~m}$. When the length of the tank is $1.17 \mathrm{~m}$, tank sloshing reduces the amplitude of the ship's roll angle by $17.0 \%$.

We can conclude that the different lengths of the tank would not change the trend of increasing or decreasing ship rolling motion. The longer tank would lead to a greater effect on the rolling motion.

Figure 24 shows the heave amplitude of the ship while the length of the ship is different. It can be seen from Figure 24 that there is little difference in the heave amplitude of the ship when the wavelength ratio is 0.463 and 0.787 . When the wavelength ratio is 2.667 , the heave motions of the ship slightly decrease.

Figure 25 shows the transverse force amplitude of the tank.

The Fy (transverse force) on the tank is generated by liquid sloshing in the tank. It can be seen from Figure 24 that the variation trend of the Fy amplitude of the tank is the same under the three working conditions, and the Fy amplitude reaches the maximum when the incident wave frequency is close to the natural frequency of ship rolling. The liquid height in the tank in Case 3 is the same as that in Case 1, but the length of the tank in Case 3 is about twice as long as that in Case 1, so the amplitude of Fy of the tank in Case 3 is about twice that of Case 1. The volume of liquid in the tank in Case 2 and Case 3 is about the same, and the Fy in Case 2 is much larger than that in Case 3 because the sloshing in Case 2 is more intense. Thus, reducing the height of the liquid in the tank could reduce the transverse force on the tank when the volume of water in the tank is constant. The average transverse force of Case 3 relative to Case 2 is reduced by $33.9 \%$. 


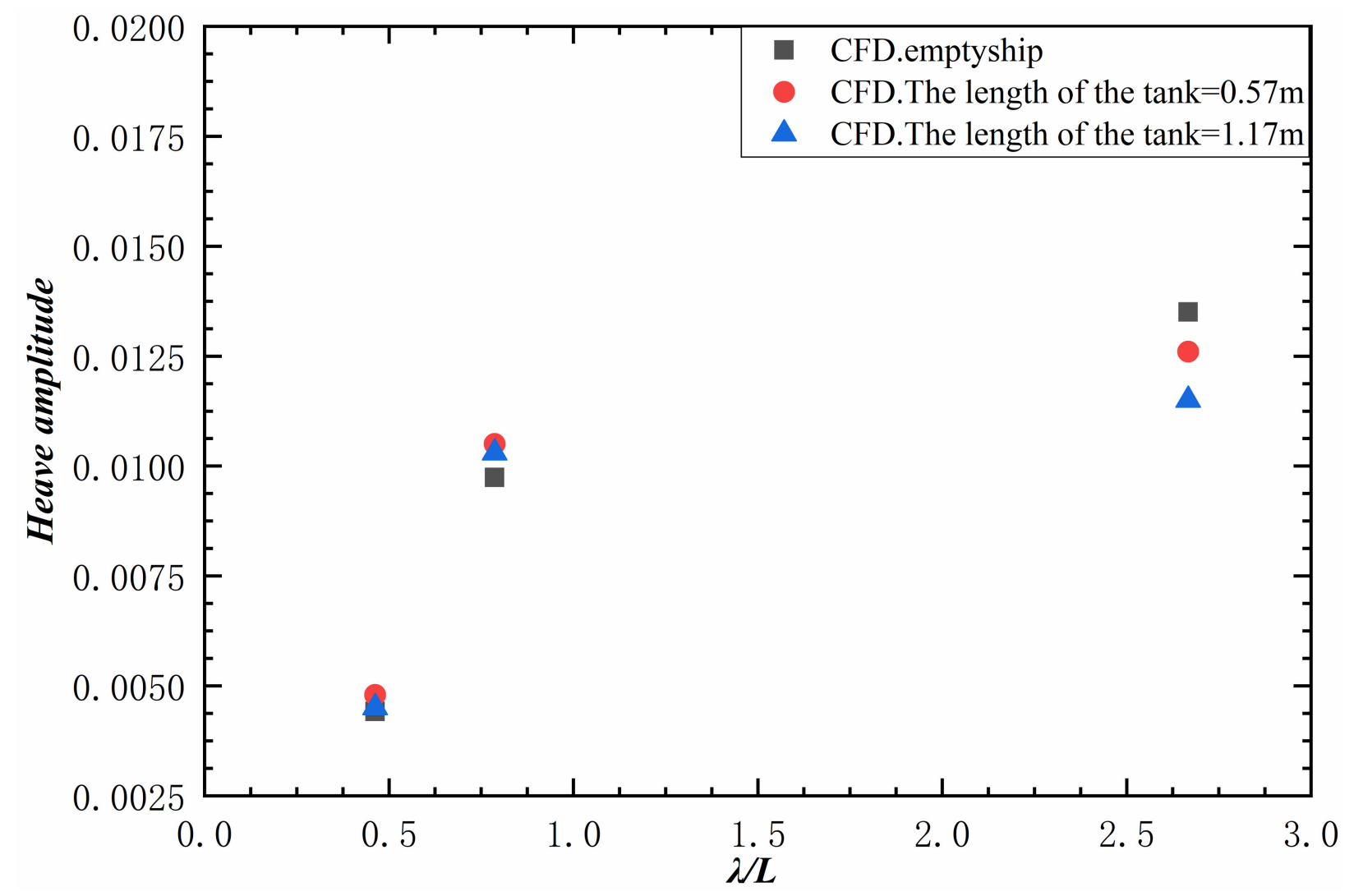

Figure 24. The heave amplitude of the ship.

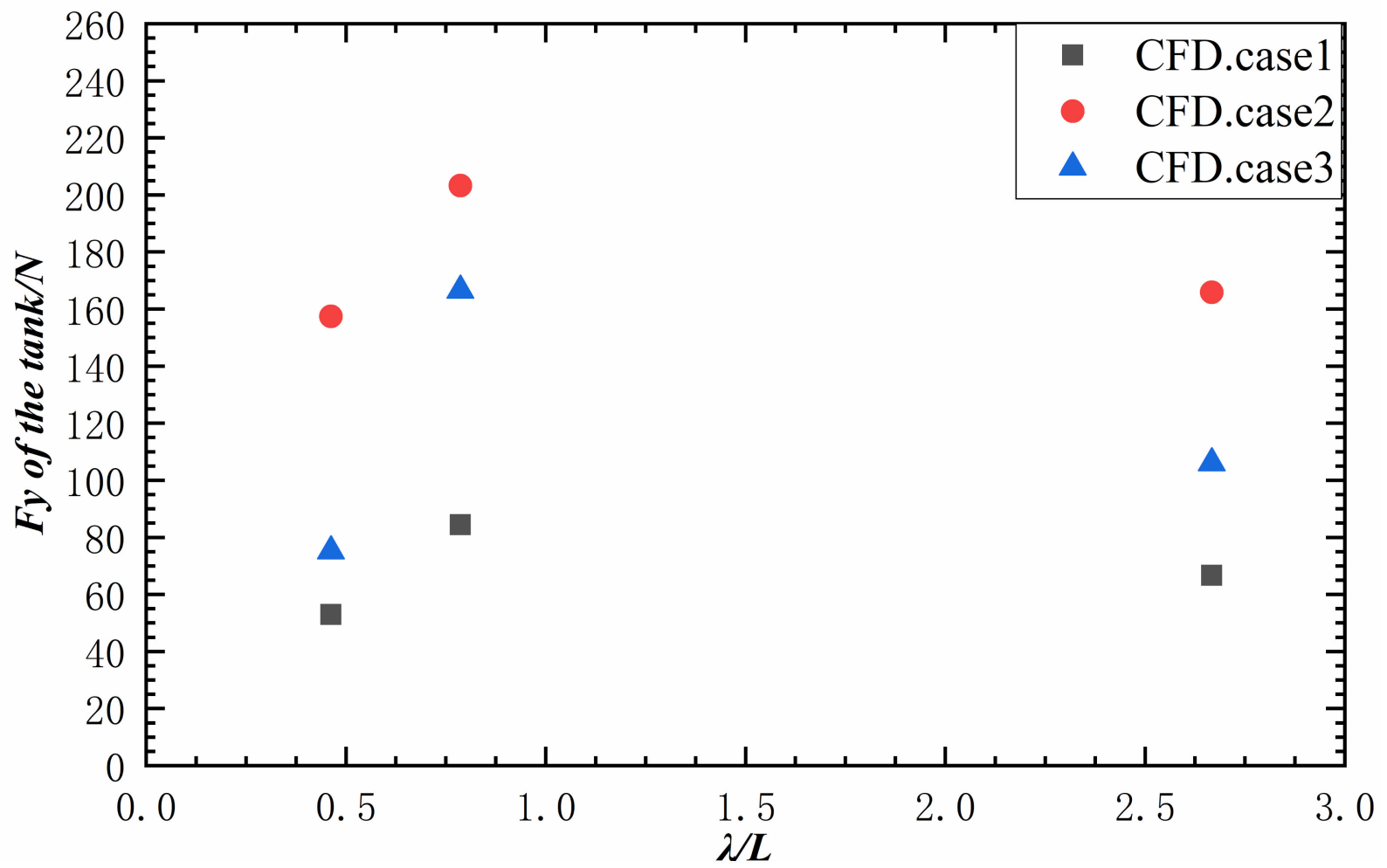

Figure 25. The amplitude of transverse force on the tank (Case 1: The size of the tank is $0.57 \times 0.57 \times 0.5 \mathrm{~m}$, and the height of liquid in the tank is $0.1 \mathrm{~m}$; Case 2: The size of the tank is $0.57 \times 0.57 \times 0.5 \mathrm{~m}$, and the height of liquid in the tank is $0.2 \mathrm{~m}$; Case 3: The size of the tank is $1.17 \times 0.57 \times 0.5 \mathrm{~m}$, and the height of liquid in the tank is $0.1 \mathrm{~m}$ ). 


\section{Conclusions}

This paper used the direct CFD simulation and experimental method to study the coupled motion response of a ship with a tank in beam waves. The model tests were carried out in the towing tank at Huazhong University of Science and Technology.

In this study, the CFD method based on the structural overset was used to study the coupling characteristics of tank sloshing and ship motion in beam waves. All the simulations were carried out by the in-house CFD solver. RANS equations were solved by the finite difference method (FDM), and the projection algorithm was used to solve the pressure and velocity. Finally, the two-equation Shear Stress Transport (SST) $k-\omega$ turbulence model was used.

We performed grid sensitivity studies and calculated the Grid Convergence Index (GCI). The simulation results are in good agreement with the experimental results, which shows that the in-house CFD solver is reliable.

The effect of liquid height inside the tank and the effect of tank length were considered. When the wavelength ratio is small, the tank sloshing causes an increase in the roll amplitude of the ship. When the wavelength ratio is large, the tank sloshing causes a decrease in the roll amplitude of the ship. In the long wave with a wavelength ratio of 2.667, tank sloshing decreases the rolling amplitude of the ship when the height of liquid in the tank is $0.1 \mathrm{~m}$, and the amplitude of the ship's roll angle is $8.3 \%$ lower than that without tank sloshing. When the wavelength ratio is 0.787 , the frequency of the incident wave is close to the natural frequency of the ship rolling, and the roll angle of the ship reaches the maximum. When the liquid height in the tank is $0.2 \mathrm{~m}$, tank sloshing increases the amplitude of the ship's roll angle by $28.6 \%$ at the wavelength ratio of 0.787 . In addition, the amplitude of the ship's roll angle increases by $12.9 \%$ when the liquid height is $0.1 \mathrm{~m}$. The influence of tank sloshing on the ship's rolling amplitude depends on the phase difference between the tank rolling moment curve and the ship rolling moment curve. The effect of the tank sloshing on the ship is small when the phase difference between the two curves is close to $\pi / 2$. Additionally, the tank sloshing promotes the rolling motion of the ship when the phase difference between the two curves is close to 0 .

Through the experimental results, we can conclude that the pressure amplitudes of different points on the bulkhead are very close to each other in the same working conditions.

At wavelength ratios of 0.463 and 0.787 , heave motions increase slightly, while at a wavelength of 2.667, heave motions are slightly decreased. The Fz of the tank is small compared to the Fz of the ship. Thus, the sloshing has little influence on the heave motion of the ship. The result is similar to research by a hybrid method [30] for a ship's response coupled with sloshing.

In the simulation, the shape of the free surface inside the tank is monitored at different times in a wave cycle, and the change of the free surface shape is different when the liquid height is different. The transverse forces on the tank in different working conditions are compared. We found that the average transverse force of Case 3 relative to Case 2 is reduced by $33.9 \%$. The results show that increasing the length of the tank can reduce the transverse force on the tank when the volume of water in the tank remains unchanged.

Author Contributions: Investigation, data curation, validation, writing — original draft and writingreview, T.H.; project administration, methodology, resources, funding acquisition, visualization and supervision, D.F.; funding acquisition and supervision, L.L.; supervision and resources, X.W.; supervision, H.J. All authors have read and agreed to the published version of the manuscript.

Funding: This research was funded by the China National Science Foundation YEQISUN Joint Funds (U2141228).

Institutional Review Board Statement: Not applicable.

Informed Consent Statement: Not applicable.

Data Availability Statement: Not applicable. 
Acknowledgments: This research was funded by the China National Science Foundation YEQISUN Joint Funds (U2141228). This essential support is greatly acknowledged.

Conflicts of Interest: The authors declare no conflict of interest.

\section{References}

1. Abramson, H.N. The Dynamic Behavior of Liquids in Moving Containers; NASA SP-106; NASA Special Publication: Washington, DC, USA, 1966; p. 106.

2. Ikeda, T.; Nakagawa, N. Non-Linear Vibrations of A Structure Caused By Water Sloshing In A Rectangular Tank. J. Sound Vib. 1997, 201, 23-41. [CrossRef]

3. Faltinsen, O.M.; Rognebakke, O.F.; Lukovsky, I.A.; Timokha, A.N. Multidimensional modal analysis of nonlinear sloshing in a rectangular tank with finite water depth. J. Fluid Mech. 2000, 407, 201-234. [CrossRef]

4. Faltinsen, O.M.; Timokha, A.N. An adaptive multimodal approach to nonlinear sloshing in a rectangular tank. J. Fluid Mech. 2001, 432, 167-200. [CrossRef]

5. Nasar, T.; Sannasiraj, S.A. Sloshing dynamics and performance of porous baffle arrangements in a barge carrying liquid tank. Ocean Eng. 2019, 183, 24-39. [CrossRef]

6. Nasar, T.; Sannasiraj, S.A.; Sundar, V. Motion responses of barge carrying liquid tank. Ocean Eng. 2010, 37, 935-946. [CrossRef]

7. Shuya, W.; Zhiqiang, H.; Gang, C. Research on Tank Sloshing and Coupling Effects on Global Roll Motion of an FLNG System. China Offshore Platf. 2015, 30, 84-92.

8. Lee, J.; Ahn, Y.; Kim, Y. Experimental study on effect of density ratio and phase transition during sloshing impact in rectangular tank. Ocean Eng. 2021, 242, 110105. [CrossRef]

9. Gurusamy, S.; Kumar, D. Experimental study on nonlinear sloshing frequency in shallow water tanks under the effects of excitation amplitude and dispersion parameter. Ocean Eng. 2020, 213, 107761. [CrossRef]

10. Bulian, G.; Cercos-Pita, J.L. Co-simulation of ship motions and sloshing in tanks. Ocean Eng. 2018, 152, 353-376. [CrossRef]

11. Green, M.D.; Zhou, Y.; Dominguez, J.M.; Gesteira, M.G.; Peiró, J. Smooth particle hydrodynamics simulations of long-duration violent three-dimensional sloshing in tanks. Ocean Eng. 2021, 229, 108925. [CrossRef]

12. Li, Y.L.; Zhu, R.C.; Miao, G.P.; Ju, F.A.N. Simulation of tank sloshing based on OpenFOAM and coupling with ship motions in time domain. J. Hydrodyn. Ser. B 2012, 24, 450-457. [CrossRef]

13. Jiang, S.C.; Teng, B.; Bai, W.; Gou, Y. Numerical simulation of coupling effect between ship motion and liquid sloshing under wave action. Ocean Eng. 2015, 108, 140-154. [CrossRef]

14. Seo, M.; Kim, Y.; Park, D. Effect of internal sloshing on added resistance of ship. J. Hydrodyn. Ser. B 2017, 29, 13-26. [CrossRef]

15. Su, Y.; Liu, Z.Y. Coupling effects of barge motion and sloshing. Ocean Eng. 2017, 140, 352-360. [CrossRef]

16. Shah, Z.; Sheikholeslami, M.; Kumam, P.; Shutaywi, M.; Thounthong, P. CFD Simulation of Water-Based Hybrid Nanofluid Inside a Porous Enclosure Employing Lorentz Forces. IEEE Access 2019, 7, 177177-177186. [CrossRef]

17. Fatinsen, O.M. A numerical nolinear method of sloshing in tanks with two-dimensional flow. J. Ship Res. 1978, 3, 193-202. [CrossRef]

18. Wang, X.; Liu, L.; Zhang, Z.; Feng, D. Numerical Study of the Stern Flap Effect on Catamaran' Seakeeping Characteristic in Regular Head Waves. Ocean Eng. 2020, 206, 107172. [CrossRef]

19. Liu, L.; Wang, X.; He, R.; Zhang, Z.; Feng, D. CFD prediction of stern flap effect on Catamaran seakeeping behavior in long crest head wave. Appl. Ocean Res. 2020, 104, 102367. [CrossRef]

20. Menter, F.R. Two-equation eddy-viscosity turbulence models for engineering applications. AIAA J. 1994, 32, 1598-1605. [CrossRef]

21. Osher, S.; Sethian, J.A. Fronts propagating with curvature-dependent speed: Algorithms based on Hamilton-Jacobi formulations. J. Comput. Phys. 1988, 79, 12-49. [CrossRef]

22. Carrica, P.M.; Wilson, R.V.; Noack, R.W.; Stern, F. Ship motions using single-phase level set with dynamic overset grids. Comput. Fluids 2007, 36, 1415-1433. [CrossRef]

23. Mascio, A.D.; Broglia, R.; Muscari, R. On the application of the single-phase level set method to naval hydrodynamic flows. Comput. Fluids 2007, 36, 868-886. [CrossRef]

24. Rossi, R.; Larese, A.; Dadvand, P.; Oñate, E. An efficient edge-based level set finite element method for free surface flow problems. Int. J. Numer. Methods Fluids 2013, 71, 687-716. [CrossRef]

25. Burg, C.O.E. Single-phase level set simulations for unstructured incompressible flows. In Proceedings of the 17th AIAA Computational Fluid Dynamics Conference, Toronto, ON, Canada, 6-9 June 2005.

26. Li, T.; Yan, C. Investigation of automatic generation technique for two-dimensional DRAGON grid. Acta Aerodyn. Sin. 2005, 23, 88-92.

27. Zhang, Z.; Guo, L.; Wei, P.; Wang, X.; Feng, D. Numerical Simulation of Submarine Surfacing Motion in Regular Waves. Iran. J. Sci. Technol. Trans. Mech. Eng. 2020, 44, 359-372. [CrossRef]

28. ITTC. International Towing Tank Conference. In Proceedings of the CFD General Uncertainty Analysis, Verification and Validation Methods and Procedures, Venice, Italy, 8-14 September 2002.

29. Celik, I.B.; Ghia, U.; Roache, P.J.; Freitas, C.J. Procedure for Estimation and Reporting of Uncertainty Due to Discretization in CFD Applications. J. Fluids Eng. 2008, 130, 7. 
30. Lyu, W.; Riesner, M.; Peters, A.; el Moctar, O. A hybrid method for ship response coupled with sloshing in partially filled tanks. Mar. Struct. 2019, 67, 102643. [CrossRef] 